\title{
Trilemma or Dilemma: Inspecting the Heterogeneous Response of Local Currency Interest Rates to Foreign Rates
}




\section{WP/16/75}

\section{IMF Working Paper}

\section{Trilemma or Dilemma: Inspecting the Heterogeneous Response of Local Currency Interest Rates to Foreign Rates}

by Luca Antonio Ricci and Wei Shi

IMF Working Papers describe research in progress by the author(s) and are published to elicit comments and to encourage debate. The views expressed in IMF Working Papers are those of the author(s) and do not necessarily represent the views of the IMF, its Executive Board, or IMF management. 


\title{
IMF Working Paper
}

Western Hemisphere Department

\section{Trilemma or Dilemma: Inspecting the Heterogeneous Response of Local Currency Interest Rates to Foreign Rates}

\author{
Prepared by Luca Antonio Ricci and Wei Shi
}

Authorized for distribution by Alfredo Cuevas and Era Dabla-Norris

March 2016

\section{IMF Working Papers describe research in progress by the author(s) and are published to elicit comments and to encourage debate. The views expressed in IMF Working Papers are those of the author(s) and do not necessarily represent the views of the IMF, its Executive Board, or IMF management.}

\begin{abstract}
This paper studies the heterogeneous response across countries of local currency interest rates to foreign and domestic factors, thus contributing to the discussion on the policy trilemma in international economics. On average, floaters appear to be less affected by the U.S. in the short run (up to about one year). However, there is large cross-country heterogeneity in the response: floaters that care less about domestic objectives, exhibit stronger fear of floating, or show higher co-cyclicality with the U.S., respond more to foreign rates. This suggests that floating does not necessarily imply a lack of response of local policy rates to foreign ones, but seems to allow independence when needed. Moreover, the effect of foreign rates on the short end of the local interest rate curve seems to operate mainly via the foreign influence on local policy rates, thus suggesting that central banks may be themselves the source of conduit of the "global credit cycle" discussed by Rey (2014). At the same time, most countries face the equivalent of a "Greenspan conundrum" as their long term rates are mainly influenced by foreign factors.
\end{abstract}

JEL Classification Numbers: E43, E52, F36, F65

Keywords: Monetary policy, trilemma, international financial market spillovers, interest rates Author's E-Mail Address: 1ricci@,imf.org, wshi@imf.org 


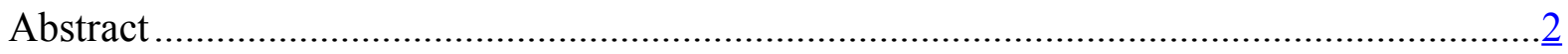

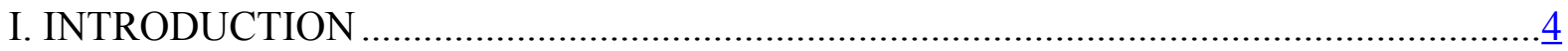

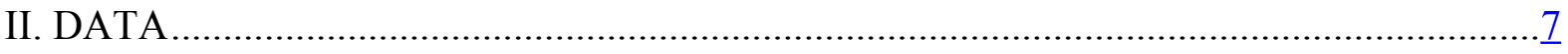

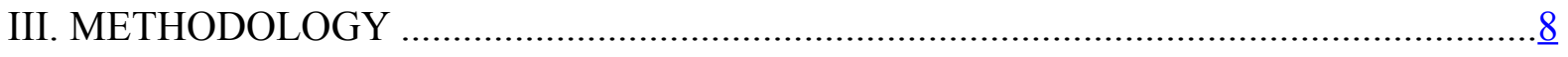

IV. RESULTS ..................................................................................................... 11

A. Creating a short term (ST) Baseline: USM and USYC Models ..........................11

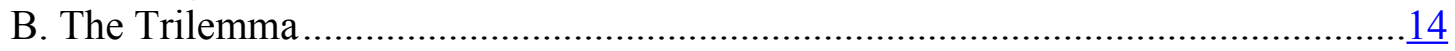

C. Why Not All Floaters Appear Independent?..................................................

D. Do Foreign Rates Generate the Equivalent of a Greenspan Conundrum for Central

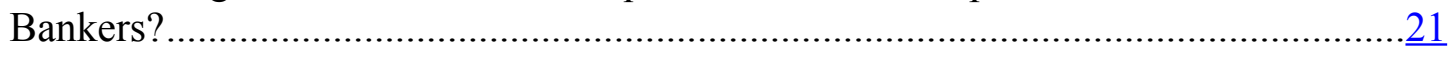

V. ROBUSTNESS CHECKS ............................................................................... 23

A. Do Global Factors and Exchange Rate Alter The Picture? ..................................23

B. Baseline versus Error-Correction Model (ECM) …......................................

C. Adding Output Gap .................................................................................. 24

D. Structural Change During the Recent Global Crisis ...................................... 25

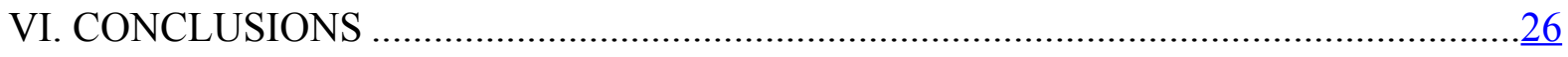

\section{Tables}

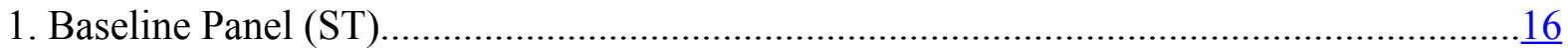

2. Why Floaters Have Different Pass-through (Floaters only, ST) .................................. 20

\section{Figures}

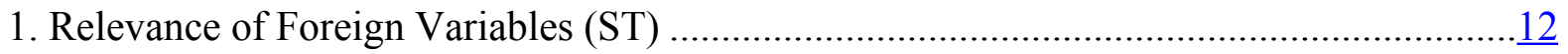

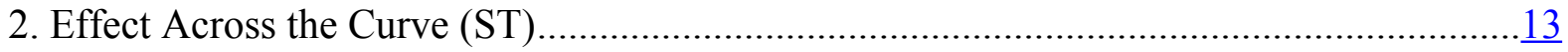

3. Floating/Capital Controls Buy Short-Term Independence ...........................................15

4. USM Panel Mean-Group Estimates and Confidence Interval (ST) ................................17

5. Following U.S. vs. Controlling Inflation (Floaters only, ST) ......................................18

6. Interest Rate vs. Reserve Intervention (Floaters only, ST) .........................................18

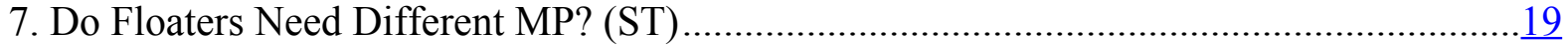

8. Effect Across the Curve with Local Policy Rate (ST) ................................................22

9. Robustness-Baseline vs. Error-Correction (ST) .....................................................24

10. Robustness - Output Gap (ST) ....................................................................... 25

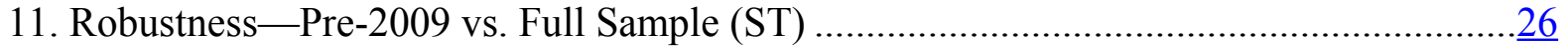




\section{Appendix}

Additional Material.

\section{Appendix Tables}

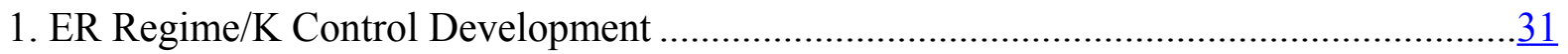

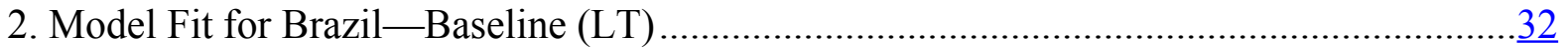

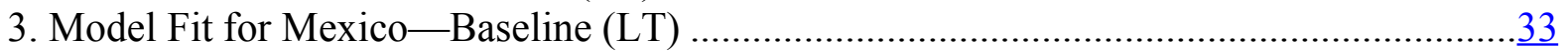

4. Floating Allow More Reaction to Domestic Inflation (ST) ..............................................34

5. Country-Specific Response to U.S. over Different Horizon..............................................34

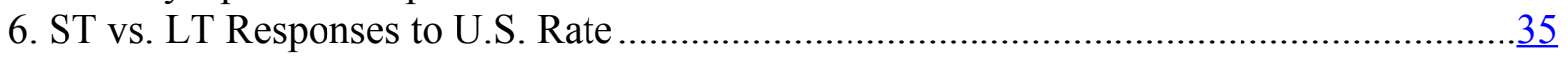

7. Greenspan Conundrum for EM (LT \& ST) ………….................................................

8. Effect Across the Curve (ST, Global Factors \& NEER) ………………………...............

9. Response to U.S. Rate vs. ER Regime/K Control ………..................................................

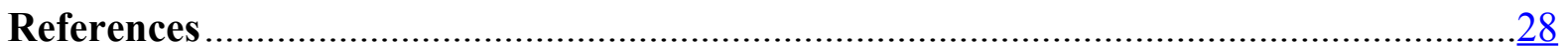




\section{INTRODUCTION ${ }^{1}$}

To what extent countries enjoy monetary policy independence in choosing their policy rates? Can they rely on the choice of the exchange rate regime or the degree of capital controls to tilt the balance? And to what extent do they control the local yield curve? These questions have been crucial for policymakers and academics for decades. And have become even more relevant in recent years, when monetary policy (MP) in advanced economies has been exceptionally expansionary in order to cope with the recent global recession. They will remain extremely relevant as the global recovery unfolds with substantial heterogeneity of economic cycles across countries and hence different needs for monetary policy stances.

Yet the academic literature is quite divided on this question, maybe more so today than ever. A long-standing position, recently restated very elegantly by Obstfeld (2015), supports the existence of an international policy trilemma: a country can insulate itself, at least in the short run, from foreign monetary policy via either capital controls or a floating exchange rate regime. The strong process of capital account liberalization over the past decades implies much lower reliance on capital controls as a policy instrument, while preference for floating remains significant (see Appendix Figure 1). However, Rey (2013 and 2014) argues that a global credit cycle operates like a tsunami in affecting countries, regardless of their exchange rate regime.

This paper contributes to this discussion by studying in particular the cross-country heterogeneity of the short-run response of a broad set of local currency interest rates to foreign rates, controlling for domestic factors and other foreign factors. It therefore studies the impact of foreign factors on the whole curve of local rates.

First, the diversity of response allows zooming in within the contentious group of floaters, some of which appear to follow foreign rates while others do not. Understanding whether such difference is associated with policy objectives is essential to assess the extent of monetary policy independence. In other words, it is not enough to find strong relation of local policy rates with foreign ones to dismiss independence. For example, imagine such strong relation for a floater is explained by factors (e.g. a high correlation of the business cycle) that would drive such a policy choice. Then, such strong response would not imply lack of MP independence, but simply a justified choice to follow a similar MP.

Second, the variety of local currency rates considered along the rate curve allows investigating also the transmission channel through which changes in foreign interest rates affect the domestic financial market. Central banks constantly worry about their ability to

\footnotetext{
${ }^{1}$ We would like to thank participants in the Jun. 2014 IMF/WHD, Sep. 2014 IMF/Surveillance Meeting, Oct. 2014 WB-LAC, Nov. 2014 IADB, Nov. 2014 WB, Feb. 2015 IMF/WHD-macro seminars, May 2015 The Graduate Institute of International and Development Studies seminar, as well as Tam Bayoumi, Olivier Blanchard, Diego Cerdeiro, Giovanni Dell'Ariccia, Metodij Hadzi-Vaskov, Gian Maria Milesi-Ferretti, Maurice Obstfeld, Sam Ouliaris, Ugo Panizza, Peter Pedroni, Andrea Pescatori, Alejandro Werner, and Charles Wyplosz for invaluable comments. We would also like to thank Krippner, Wu, Xia, Lombardi, and Zhu for sharing data with us. Daniela Cortez offered invaluable research assistance.
} 
influence their local rate curve, which is another way of assessing independence, in a highly integrated global financial market. This issue is closely related to Rey (2014) argument about the presence of a global credit channel which influences directly local rates (and local economic conditions). Does the influence of foreign rates on the local currency interest rate structure act in parallel to the effect of foreign rates on the local policy rate? Or does it act mainly indirectly via affecting the local policy rate, which in turn shifts the local yield curve? And is such effect different at different ends of the curve? Is there an equivalent of a Greenspan conundrum for all countries? These questions highlight another angle of MP independence, which is related to the ability of central banks to isolate the domestic monetary transmission mechanism from foreign factors.

\section{Recent Literature on Trilemma, Definition of MP Independence, and Our Strategy}

Frankel et al. (2004) view MP independence as the ability of countries to set their nominal interest rates. Accordingly, countries are considered as enjoying permanent monetary autonomy if their interest rates show limited pass-through from the most relevant foreign rates (as judged from trade and financial market linkage), in the long run. Conversely, countries are thought of having temporary monetary autonomy if it takes relatively long time for local interest rates to fully reflect changes in the most relevant foreign interest rates. This definition offers a simple strategy for empirical studies. By examining the short-term interest rate in a cross-country panel, they find that there is limited scope for permanent monetary autonomy regardless of the exchange rate regime, but floaters show slower transmission of foreign interest rate changes to local rates, and thus floaters are regarded as enjoying more temporary monetary autonomy.

Though such results fit naturally with the common belief that having a floating exchange rate allows the monetary authority more room to maneuver, they were challenged recently by Rey (2013). She identifies strong common movements of cross-border capital flows, the international financial cycle, and claims that these capital flows, together with the leverage of global financial institutions, transmit monetary conditions present in core economies (such as the U.S.) into other economies. Quite importantly, those that let their exchange rates float against core countries are no exceptions. However, this has not been considered the traditional way of looking at MP independence. As Klein and Shambaugh (2013) put it, after recognizing the importance of the international credit cycle: "It is incorrect to say that monetary policy has no effect because there is also a credit channel, just as it would be incorrect to say that monetary policy has no effect because there is also fiscal policy."

Obstfeld (2015) recognizes that the highly-integrated global financial market complicates the policy-making of central banks by adding financial stability to their objectives. However, he finds that floaters still enjoy more MP independence, in the sense that their short term interest rates are insulated from quick transmission of foreign rate changes, and thus can focus more on addressing domestic objectives.

We will look at MP independence from both of the angles discussed above, one more strictly related to the independence of the monetary policy instrument and the other more related to the lack of foreign influence in the monetary transmission channel. It becomes then essential to be explicit about the two working definition of MP independence adopted in this paper. 
First, we focus on the short-term response of domestic local currency policy rates to foreign rates to assess independence. Indeed, policymakers are more interested in their immediate (short-term) ability to make autonomous choices in monetary policy. In the long run policy rates can be expected to co-move in today's globalized financial world (as also documented in our paper) to the extent that inflation differentials are stationary (which has become more and more the case over the past decades, in part as a consequence of the wider adoption of inflation targeting to anchor inflation expectations; see Davis (2014)).

More precisely, in this first angle, we consider MP independence to be mainly about whether a country's policy rate reaction to U.S. policy rate is related to policy choices, by analyzing: a) the degree of the short-run response of local policy rates to foreign ones; $b$ ) the extent to which such degree depends on a policy choice such as: b1) the desirability to respond to domestic factors, b2) the need to use interest rates to address fear of floating, or b3) the need to have a different monetary policy, for example because of weak business cycle correlation). For peggers, lack of independence would be ascribed simply to a high correlation with foreign rates, while for floaters, such a high correlation would not be considered lack of MP independence if it can be explained by policy choices. Note that although the main focus is on the short term, we also check the response in the long run and at different time horizons, particularly to assess at what horizon independence seems to vanish.

The second angle evaluates MP independence by inspecting the next step in the monetary transmission channel: we focus on how other local interest rates move with the local policy rate as opposed to foreign rates. The intention is to understand whether there is a direct effect of foreign rates on the local rate curve (lack of independence in the monetary transmission mechanism) or such apparent correlation simply reflects the correlation between domestic and foreign policy rates. This helps gauge whether the local policy rate is an effective policy instrument, and is related to Rey (2014) argument that there is strong foreign influence on the domestic transmission channel. For this purpose, we employ a broader coverage of the interest rate structure than other studies (for example Obstfeld, 2015), from 3-month rates to the 10-year nominal government bond yield.

In light of the size of the U.S. economy and the important role it plays in the international financial market, along with the data availability, U.S. rates are chosen as the reference foreign rates. Indeed, the U.S. policy rate explains 70 percent of the first principal component of the policy rates of the largest 30 countries since 2000 (85 percent since 1995, for 17 countries). This strategy is consistent with several academic contributions, such as Rogers, et al. (2014), who argue that U.S. monetary policy spillover to other advanced economies are much larger than the spill-backs. ${ }^{2}$ In light of this strategy, we exclude euroarea countries from the sample, apart from Germany.

Our initial empirical findings are consistent with the literature that floaters have more MP independence in the short run. Yet, the distinguishing feature of our work is that our cross-

\footnotetext{
${ }^{2}$ Recent episodes of the influence of euro area monetary policy developments on global rates would require a separate exercise, as the sample is not long enough for our analysis. For an analysis of the spillovers from four center economies (the U.S., Japan, the Eurozone and China), see Aizenman et al. (2015).
} 
country study of heterogeneous interest rate responses uncovers a much richer picture than a simple grouping of countries by floaters versus peggers would reveal. By linking such heterogeneous responses to country-specific policy objectives, we are able to conduct our analysis of MP independence on a broader basis rather than simply focusing on the lack of foreign influence. A few recent papers (Aizenman et al. 2015; Edwards 2015) are closely related and offer consistent results, although the methodology makes them more suitable for an assessment of long-term spillovers than monetary policy independence (the analysis is in "levels" as opposed to "changes").

The rest of the paper is organized as follows. Section II and Section III outline the data and empirical strategies we use, while major results and economic discussions are presented in Section IV. Various robust checks are given in Section V. We conclude with plans for future works in Section VI.

\section{DATA}

Data used in the analysis consist of an unbalanced panel at monthly frequency, including both advanced economies and emerging markets. The rates of interest employed in the analysis cover a broad span of the yield curve: the policy rate, which is under control of the central banks, as well as more market-determined rates such as the short-term 3-month interbank rate, bank deposit and lending rates, the 2-year government bond yield, and the long term 10-year government bond yield. All interest rates are denominated in local currency. We also consider the sovereign spread related to U.S. dollar bonds, to double check the effects on the long end of the local curve. The policy rates are collected from Haver Analytics, bank deposit and lending rates are from IFS, while the interbank rates, government bond yields and the sovereign spread are gathered from Bloomberg.

As other studies in the literature, we use the Chicago Board Options Exchange Market Volatility Index (VIX) as a proxy for the global financial market uncertainty, which is strictly related to flight to quality and the relative appetite for assets of large and safe advanced economies (like the U.S.) versus the assets of other countries (especially emerging markets). For the post-2009 period when the nominal policy rate in the U.S. has been effectively staying close to zero, we employ the shadow policy rate estimates made by several papers in order to quantify the impact of the unconventional monetary policy conducted by the Fed (more below).

The major domestic variable used in the analysis is inflation measured by consumer price index (CPI, from INS), the only monthly economic cycle indicator with a reasonably long history and a substantial cross-country coverage. We perform robust check with industrial production (from HAVER and IFS) for countries having long enough series, as well as with annual output gap (from WEO) spliced into monthly data (the latter obviously not up to an adequate standard for the baseline regressions).

The two major country characteristics employed are the exchange rate regime and the capital control regime. The exchange rate regime classification (a zero-one dummy) follows Jay Shambaugh (2004) index of whether a country pegs to the U.S. or not (based on actual 
behavior rather than declared status). The capital controls measure is the Quinn-Toyoda index (Quinn 1997, and Quinn and Toyoda, 2008). ${ }^{3}$

\section{METHODOLOGY}

The specification is based on the monetary reaction functions under different regimes. For comparability of specification among different rates, this is then generalized to non-policy interest rates.

\section{Nesting Two Monetary Reaction Functions}

Classical international economic theory asserts that a country with a fixed exchange rate regime and open capital market needs to follow the monetary policy of the foreign country it pegs to, thus the two policy rates may only differ by a risk premium (which should change with domestic characteristics as well as global appetite for the country assets):

$$
i_{\text {fix_kopen }}=g_{\text {fix_kopen }}\left(i^{*}\right)+h_{\text {fix_kopen }}(\text { risk })
$$

Where $i$ is the domestic interest rate, $i *$ is the foreign rate, $g()$ and $h()$ are functions.

Exchange rate flexibility or capital controls should give a country more freedom to tailor its monetary policy to domestic targets, such as inflation, output, etc. Therefore, a Taylor-type inflation targeting rule could be used to characterize such behavior, similarly supplemented by a risk factor.

$$
i_{\text {flex_kctrl }}=g_{\text {flex_kctrl }}(\pi, y, \ldots)+h_{f l e x_{-} k c t r l}(\text { risk })
$$

In reality, very few countries follow these extreme regimes, and most countries are likely to lie in between. It is therefore best to adopt for each country a specification that nests the two monetary reactions functions and then see how results related to available proxies for the various regimes. The nested reaction function would respond to both domestic and external factors, such as the foreign interest rates and the global financial market uncertainty (serving as proxy for global financial uncertainty and appetite for riskier assets).

\section{Estimation Approaches}

Thanks to the relative data abundance, we are able to directly work on individual country and perform country-specific regression of the following form:

$$
i_{t}^{j, c}=\alpha^{j, c}+\beta^{j, c} \cdot \boldsymbol{I}_{t}^{j, u s}+\gamma^{j, c} \cdot V I X_{t}+\theta^{j, c} \cdot \boldsymbol{X}_{t}^{j, c}+\varepsilon_{t}^{j, c}
$$

We regress the local interest rate $i$ of type $j$ in country $c$ on the constant, the U.S. interest rates ( $I$, which will be specified in more details below), the VIX index, and domestic factors

\footnotetext{
${ }^{3}$ We check the robustness of our key results against several alternative measures of exchange rate regime or capital controls (results available upon request).
} 
$(X)$, such as inflation in the baseline model (and output gap, industrial production, local policy rate, etc. in robustness checks). Our baseline setup favors simple OLS where both dependent and independent variables are expressed in first difference, which captures the short term (one-month horizon) responsiveness of local interest rate to various external and domestic factors (many countries' interest rates have unit-roots, but are co-integrated with the specified regressors). ${ }^{4}$ In Section $\mathrm{V}$, we perform robustness check via an error-correction model setup where the local interest rate can have different short-term responses to regressors and different converging speeds across countries, but all countries share the same long-term relationship. ${ }^{5}$

We then inspect the distribution of coefficients estimated via the first-stage country-bycountry regressions. In particular, we zoom in on the local policy rate regression and examine if MP is conducted differently according to country-specific characteristics, such as whether the exchange rate is fixed or floating, or whether there are capital controls imposed, etc.

Results from the country-specific analysis are then double-checked through the following panel regression estimated for both the full sample and for subsamples distinguished by different regimes of exchange rate flexibility or capital market openness:

$$
i_{c, t}^{j}=\alpha^{j}+\beta^{j} \cdot \boldsymbol{I}_{u s, t}^{j}+\gamma^{j} \cdot V I X_{t}+\theta^{j} \cdot \boldsymbol{X}_{c, t}^{j}+\varepsilon_{c, t}^{j}
$$

Variables shown in the panel regression are the same as in the country-specific regressions. The panel regression sample also has the same coverage as the country-specific regressions, both including only countries with at least five years of data. In order to easily relate and compare the panel coefficients with the country-specific coefficients, we use the PesaranSmith mean group estimator in the panel regression.

\section{The Baseline Economic Models}

There are two main economic models underlying our estimation, with different focus on the asset substitutability in the international financial market. The Matching Model (USM) emphasizes the international substitutability within asset class, while the Yield Curve Model (USYC) places more weight on the substitutability across asset classes. Both models in the parsimonious baseline share a few common variables, i.e., the financial market uncertainty VIX, and the domestic inflation measured by the year-on-year change in CPI with one-month lag.

For each type of the local interest rates, the Matching Model uses as right-hand-side foreign rate $\left(\boldsymbol{I}_{t}^{j, u s}\right.$ in Equation (1) or $\boldsymbol{I}_{u s, t}^{j}$ in Equation (2)) the corresponding type of U.S. interest rate, while the U.S. 10-year government bond yield is employed in the local EMBI spread regression. For example, when explaining the interbank rate of country $c$, we use the U.S.

\footnotetext{
${ }^{4}$ According to the country-by-country Durbin-Watson unit root test, only a small fraction of countries in the regression sample reject the null hypothesis at 10 percent level. The baseline model strongly rejects the null hypothesis of no co-integration for the regression in levels.

${ }^{5}$ Refer to Section V for more details on the error-correction model structure and results.
} 
interbank rate. The short-term interest rate in the U.S. flattens out in the post-2009 period, hence the effect of the Fed's unconventional monetary policy (UMP) on other countries cannot be captured by short-term U.S. rates. For this reason, we include the estimated shadow policy rate in the regression for every local interest rate with maturity up to two years, under the assumption that the effect of UMP would be proxied by the shadow rate. ${ }^{6}$ Analysis of the local 10-year government bond yield and the emerging market sovereign spread is done without the U.S. shadow policy rate, since the effect of UMP should be directly captured by the U.S. long-term interest rate movements.

The Yield Curve Model, on the other hand, focuses more on how the local interest rates respond to movements of the whole U.S. yield curve. We proxy the U.S. yield curve via two terms in the regression (which correspond to $\boldsymbol{I}_{t}^{j, u s}$ in Equation (1) or $\boldsymbol{I}_{u s, t}^{j}$ in Equation (2)): the U.S. policy rate (the effective federal funds rate) and the differential between the U.S. 10 -year government bond yield and the U.S. policy rate, so that changes in the first term represent shifts in the whole yield curve, while movements in the second term reflect the changes in the slope. The two segments of the yield curve are treated as explanatory variables in all regressions, regardless of the type of local interest rate on the left-hand side. Moreover, it is not necessary to include the U.S. shadow rate in the Yield Curve Model since the longterm premium already captures the influence of UMP.

\section{Robustness via Augmented Models}

The robustness of the baseline model is then checked via augmented models which encompass various additional variables.

First, the estimated response of local policy rate to U.S. policy rate might simply reflect the fact that both countries are heavily influenced by the same underlying global business cycle, rather than pure U.S. interest rate pass-through. Second, central banks may choose to set interest rates in response to changes in the exchange rate. Third, the time-series movement in sovereign risk premia would not only depend on global risk factors (captured by the VIX), but would also reflect movements in domestic risk factors (captured by country sovereign spreads which are not included in the baseline model as they reduce the sample substantially). To address these concerns, we augment our simple baseline models by including these relevant factors and check the robustness of the results.

The common global cycle is proxied via three variables: international oil price inflation, global inflation and global economic activity, the last two being proxied by the principal component of inflation and of growth in industrial production (IP) of individual countries,

\footnotetext{
${ }^{6}$ The U.S. shadow policy rate is set to zero for the pre-2009 period, and the average of the three estimates proposed in the following papers: Krippner (2013), Wu and Xia (2014), and Lombardi and Zhu (2014). All three papers use information on the long end of the U.S. yield curve to characterize the impact of unconventional monetary policy. Lombardi-Zhu also utilizes the size of Fed's balance sheet and other quantitative easing related variables in the estimation. The baseline Matching Model includes only the shadow rate, but the estimated coefficients are robust if - at the same time - a post-2009 time dummy is included.
} 
respectively. ${ }^{7}$ Then, the lag of the year-on-year change in the nominal effective exchange rate is included in the augmented models to capture the exchange rate pressure faced by the monetary authorities. The sovereign risk premium for emerging markets is proxied by the EMBIG spread, and for all other countries by the five-year credit default swap. When we investigate whether the effect of U.S. rate onto local rates (excluding the policy rate) occurs directly or indirectly via the local policy rate, we also add the local policy rate to the augmented regressions for non-policy rates.

\section{RESULTS}

In this section, we first present the key results for the short term (ST) country-specific baseline models, analyzing the relevance of the external factors as well as discussing the empirical distribution of the coefficients. Then we zoom in on local policy rate regression and move on to the main issue of the paper, the dilemma-trilemma debate. Panel regression outcomes are also presented as a consistency check for the country-specific results. Finally, we explore the heterogeneity of country coefficients and relate it to policy choices.

\section{A. Creating a short term (ST) Baseline: USM and USYC Models}

This section discusses the results for the country-by-country regressions related to the baseline model in equation (1), and especially the characteristics of the coefficients. The model is mainly estimated in month-on-month differences as we want to focus on the shortterm transmission of foreign variables which is more relevant than the long term one for the discussion related to the dilemma-trilemma (as a robustness check, later in Section V, we will compare the country-by-country short-term coefficients with the ones implied by an heterogeneous panel error-correction model). However, we show in Appendix Charts 2 and 3 the level regression for Brazil and Mexico, to indicate how well a model based on these few variables can capture the general pattern of the local interest rates; we also compare shortterm and long-term coefficients (see Section IV.B. and the related Appendix Figure 6).

Foreign variables appear particularly relevant. Figure 1 illustrates that foreign variables are very important in explaining the ST changes of local interest rates. The six panels compare the adjusted R-squared in the baseline model and in models solely dependent on domestic factors for the six local interest rates (hence excluding the EMBI spread). Due to the frequent changes exhibited by the interest rates over the one-month horizon, the country-specific model fit as measured by adjusted R-squared is usually moderate at between 0.05 and 0.2 . Nonetheless, it is clear that the inclusion of foreign variables (U.S. interest rates and VIX) greatly improves the fit of the model at both the short end and the long end of the local yield curve (as expected, especially at the long end). Local deposit and lending rates show relatively larger influence from domestic conditions, but nonetheless foreign conditions still seem to be highly relevant for many countries in the sample.

\footnotetext{
${ }^{7}$ For both CPI and IP series, the respective first principle component explains a large portion (over 40 percent), while the marginal value added by the subsequent principle components is relatively small (the $2^{\text {nd }}$ component adds around 10 percent). In the augmented models, we include only the first principle components.
} 


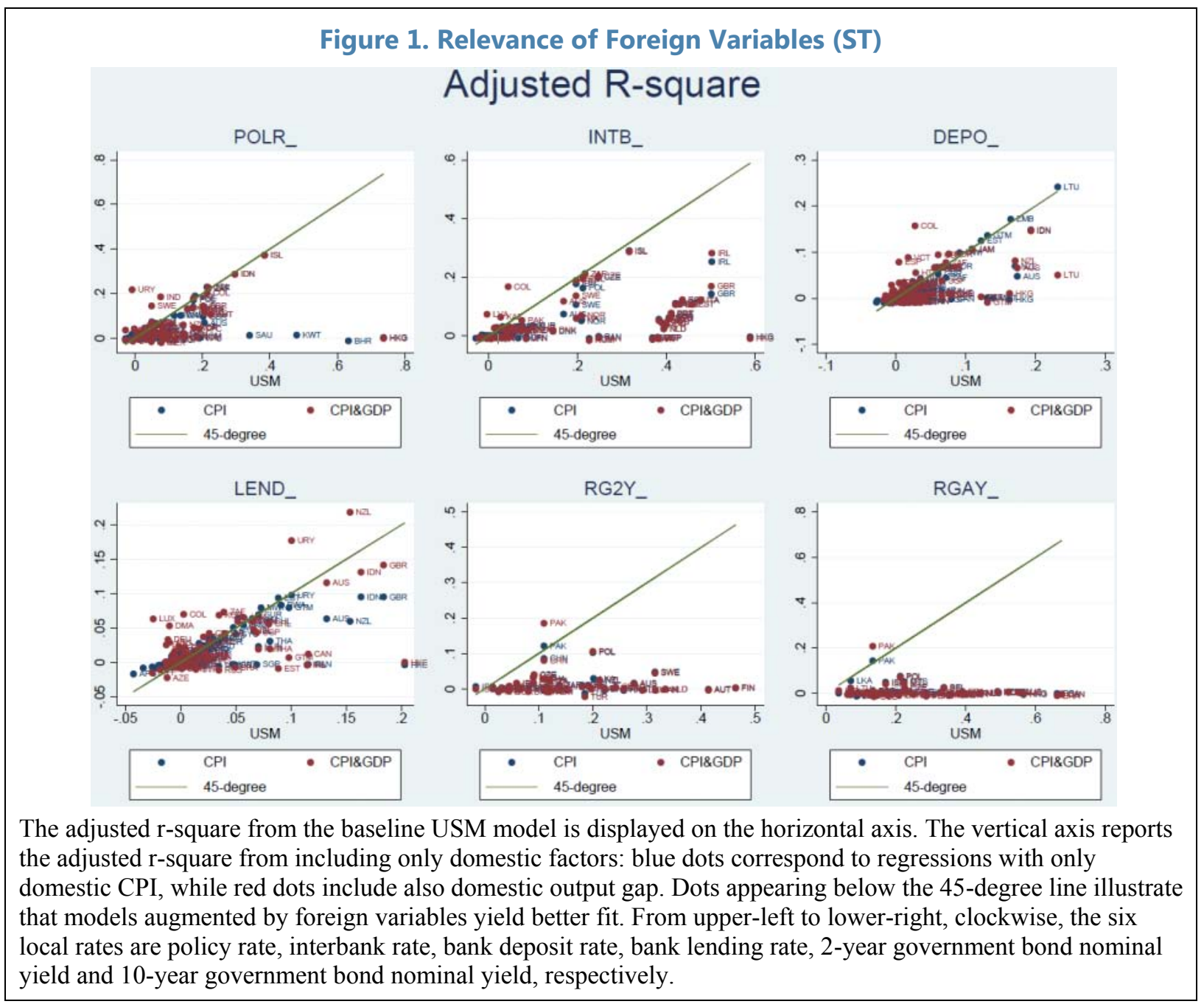

The empirical distribution of short-run coefficients offers insights as to the characteristic of such coefficients. Figure 2 presents such distributions for the country-specific regressions related to the Matching Model (upper panel) and the Yield Curve Model (lower panel), via box plots. The following can be observed:

- The response to the corresponding U.S. rates is somewhat positive for all rates and becomes stronger for longer maturities. ${ }^{8}$ The negative effect of long-term foreign rates on the spread is consistent with a less-than-one effect on long-term local rates (indeed a difference between these two coefficients equal to one would indicate that local currency and foreign currency interest rates move by exactly the same amount). It is worth noting that the U.S. non-policy interest rates react almost one-to-one to the

\footnotetext{
${ }^{8}$ It may appear as puzzling (and would deserve further investigation) the result that some coefficients are negative. However when bearing in mind that theory would suggest that the distribution of coefficients for floaters should be centered around zero (MP independence for the average floater), then it is less surprising that some coefficients are negative.
} 
U.S. policy rate even in the short run (those coefficients are reflected in red cross in the bottom left panels);

- VIX has a strongly positive impact on the EMBI spread, but not the local rates, possibly suggesting either that the effect of VIX on exchange rates allows the local rates to remain more insulated, or that risk goes up more for foreign currency issuances when global uncertainty rises as local currency issuances can be monetized;

- The response to U.S. shadow policy rate in the Matching Model is positive for local 2-year government bond yield, implying that the UMP in U.S. helped lower the medium term interest rates not just in the U.S. but also in other countries;

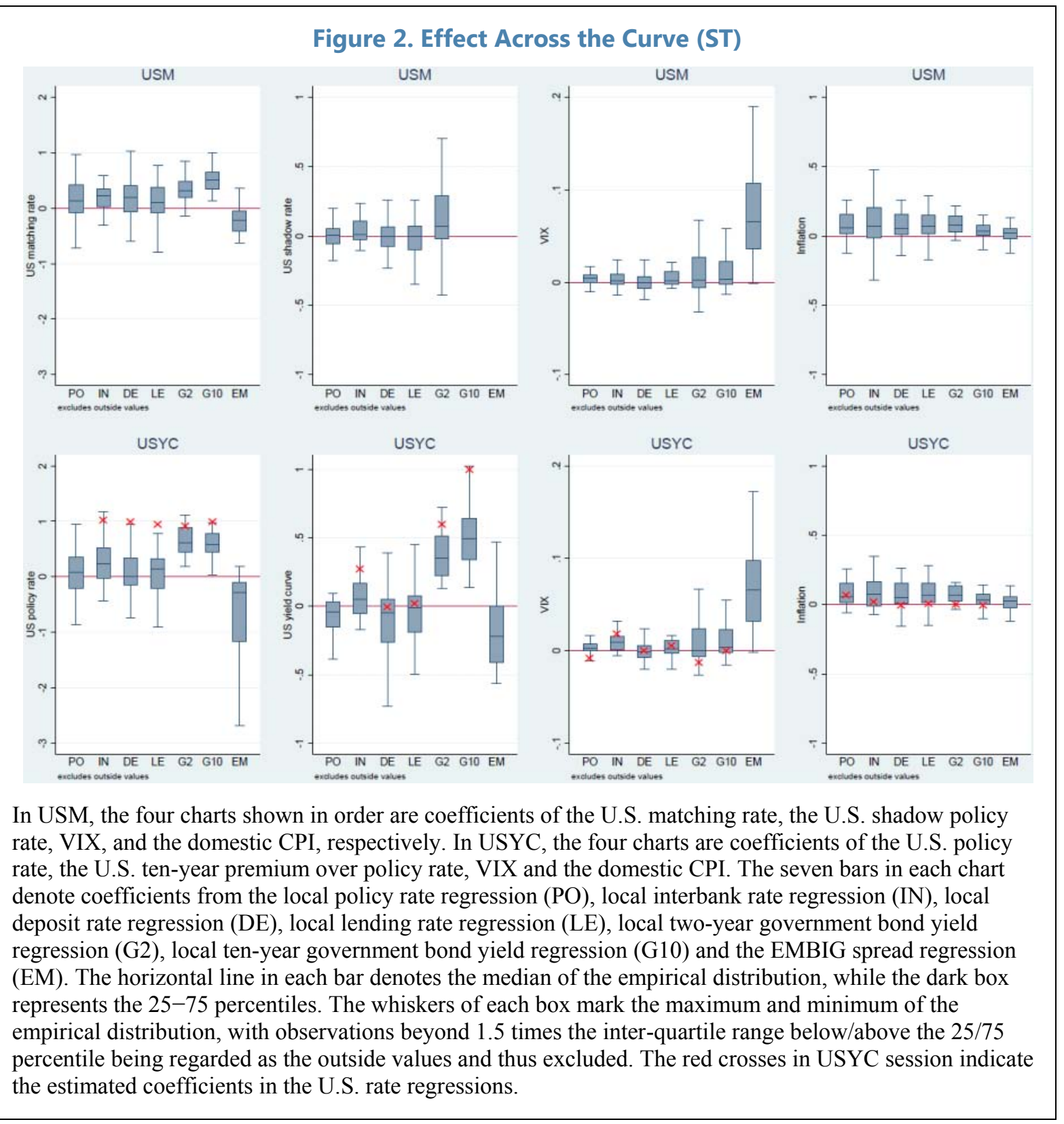


- In the Yield Curve Model, the U.S. long-term premium (the U.S. ten-year government bond yield minus the U.S. policy rate) mainly affects the medium/long term interest rates in other countries, with the expected positive sign;

- $\quad$ All local interest rate considered in the analysis respond positively to domestic inflation in both models, with medium/long term rates less affected.

\section{B. The Trilemma}

In this section, we will evaluate the relevance of the policy trilemma in light of our results on local policy rates presented in the last session.

\section{Do Floating Exchange Rate Regime (and Capital Controls) Buy Interest Rate Independence in the short term (ST)?}

The first result is that, in the short run, countries that let their exchange rate float indeed seem to have on average smaller response to the U.S. local policy rate. Figure 3 (left panel) presents the response of the local policy rate to the U.S. policy rate versus the average dummy for floating over the sample, and shows a downward sloping trend line that is marginally significant at 5 percent for both the Matching Model and the Yield Curve Model. Figure 3 utilizes all estimated U.S. policy rate coefficients (whether significant or not in the local policy rate regression), thus offering information from the full distribution of the heterogeneous responses; yet, restricting to significant country-specific coefficients only does not alter the qualitative story.

Second, peggers show clearly a high correlation with the U.S. policy rates, while floaters show a large heterogeneity of response, encompassing also the absence of foreign influence. The three peggers at the upper-left corner of the chart move, as expected, closely with the U.S. policy rate in the short run. The average pass-through among pure floaters seems to be quite close to nil, demonstrating that their policy rate is indeed less influenced by the U.S. monetary policy.

Third, what is striking in Figure 3 is the highly diverse responsiveness of floaters' policy rates. What drives such heterogeneity of response? Only if such heterogeneity could be ascribed to a "policy choice" of whether or not to follow U.S. monetary policy, it would be appropriate to interpret the results as supporting MP independence for floaters. We will investigate this point more in details below.

These conclusions drawn from the country-specific estimates are borne out by the meangroup estimator panel regressions (Table 1), where the U.S. policy rate coefficients are strongly positive and significant for pure peggers in both models, slightly positive and significant for countries that have switched exchange rate regime during the sample period (mixed exchange rate regime), and insignificant for pure floaters. At the same time, the response of policy rates to domestic inflation becomes stronger and more significant as we move from pure peggers to pure floaters (see Appendix Figure 4). 


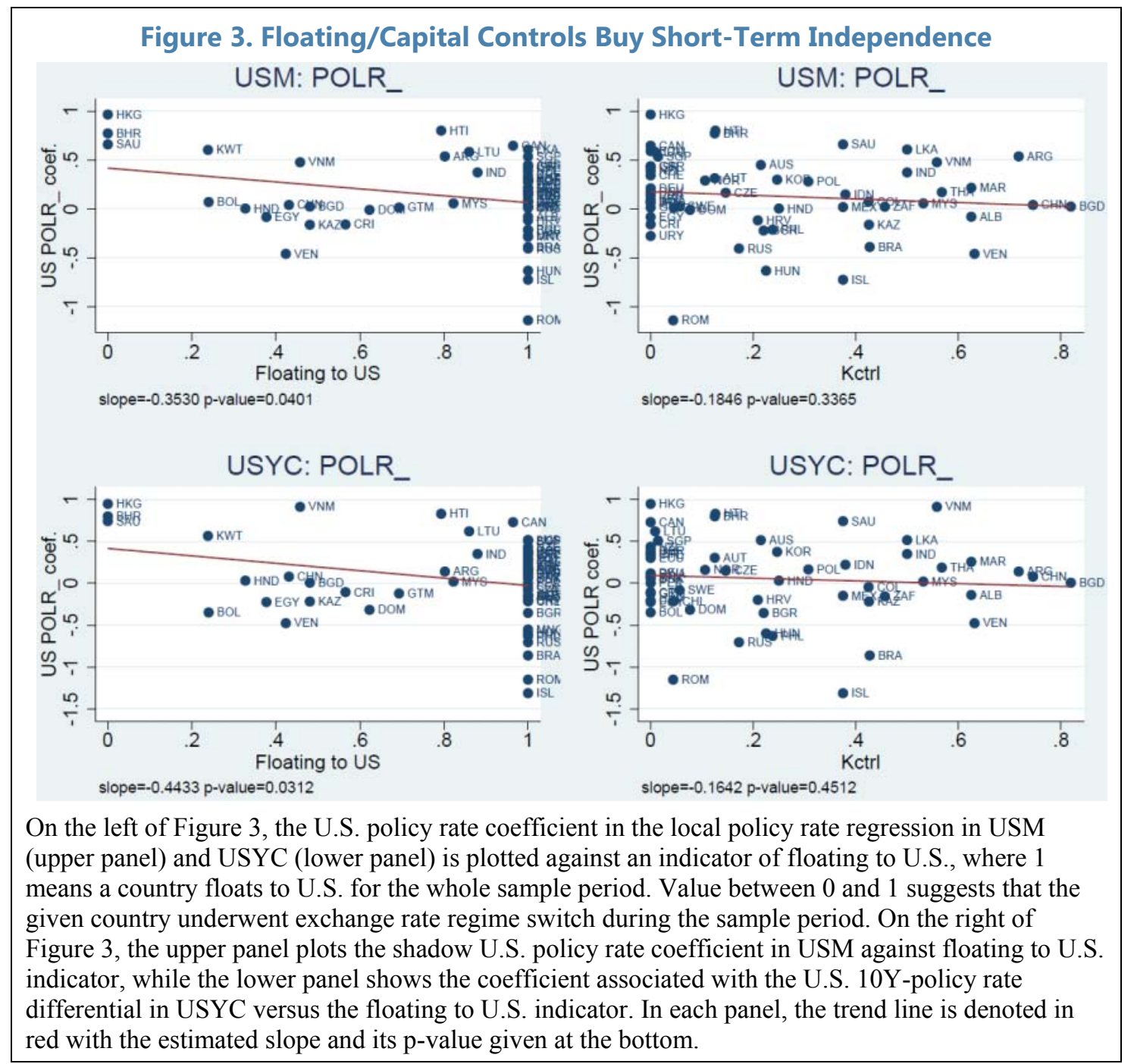

Figure 3 also studies the relationship between interest rate independence and capital controls in the short term. The story appears similar: strong capital controls allow monetary independence (the range of responses is quite close to zero for high capital controls), while countries with open capital account show a large heterogeneity of responses. However, the results are less decisive, probably due to the fact that most countries in our sample imposed only limited capital controls for a short period of time, and such temporary and partial capital controls may not be effective in reality. ${ }^{9}$

When looking at the joint role of exchange rate regimes and capital controls, it is possible to notice that capital controls help peggers retain independence (see Appendix Figure 9). However, capital controls do not seem to matter for the independence of floaters.

\footnotetext{
${ }^{9}$ Klein and Shambaugh (2013) find that episodic control-what they call "gates"- does not seem to allow more monetary independence than open capital accounts. Only the long-standing capital controls_— "walls"—-permit monetary autonomy.
} 
Going forward, we will focus more on the independence associated with floating rather than capital controls, both because of the more comprehensive availability of extreme regimes (we have 36 countries classified as pure float and zero countries classified as imposing full capital controls), and because it is more policy relevant: few policymakers nowadays would consider closing their capital account completely in order to achieve monetary policy independence, but the exchange rate regime is more easily on the policy discussion table.

\begin{tabular}{|c|c|c|c|c|c|c|c|c|}
\hline \multicolumn{9}{|c|}{ Table 1. Baseline Panel (ST) } \\
\hline \multicolumn{9}{|c|}{ MATCHING MODEL } \\
\hline VARIABLES & All & $\begin{array}{l}\text { Pure Peg } \\
\text { to US }\end{array}$ & $\begin{array}{l}\text { Mixed ER } \\
\text { Regime }\end{array}$ & $\begin{array}{c}\text { Pure Float } \\
\text { to US }\end{array}$ & Kctrl & no Kctrl & $\begin{array}{c}\text { Pure Float } \\
\text { Kctrl }\end{array}$ & $\begin{array}{c}\text { Pure Float } \\
\text { no Kctrl }\end{array}$ \\
\hline \multicolumn{9}{|l|}{ MGE } \\
\hline US policy rt & $\begin{array}{c}0.1363 * * * \\
(0.0074)\end{array}$ & $\begin{array}{c}0.7990 * * * \\
(0.0000)\end{array}$ & $\begin{array}{c}0.1867^{* *} \\
(0.0232)\end{array}$ & $\begin{array}{c}0.0395 \\
(0.5235)\end{array}$ & $\begin{array}{c}0.1313 \\
(0.1555)\end{array}$ & $\begin{array}{c}0.1376^{* *} \\
(0.0215)\end{array}$ & $\begin{array}{c}0.0054 \\
(0.9634)\end{array}$ & $\begin{array}{c}0.0438 \\
(0.5232)\end{array}$ \\
\hline VIX & $\begin{array}{c}0.0040 * * * \\
(0.0014)\end{array}$ & $\begin{array}{l}0.0053^{* *} \\
(0.0441)\end{array}$ & $\begin{array}{l}0.0059 * \\
(0.0524)\end{array}$ & $\begin{array}{l}0.0030 * * \\
(0.0269)\end{array}$ & $\begin{array}{c}0.0054 \\
(0.2185)\end{array}$ & $\begin{array}{c}0.0036 * * * \\
(0.0013)\end{array}$ & $\begin{array}{c}0.0047 * * * \\
(0.0057)\end{array}$ & $\begin{array}{l}0.0027^{*} \\
(0.0659)\end{array}$ \\
\hline L.inflation & $\begin{array}{c}0.1002 * * * \\
(0.0000)\end{array}$ & $\begin{array}{c}0.0016 \\
(0.7869)\end{array}$ & $\begin{array}{c}0.0719 * * * \\
(0.0013)\end{array}$ & $\begin{array}{c}0.1287 * * * \\
(0.0000)\end{array}$ & $\begin{array}{c}0.0210 \\
(0.2476)\end{array}$ & $\begin{array}{c}0.1204 * * * \\
(0.0000)\end{array}$ & $\begin{array}{c}0.0143 \\
(0.3441)\end{array}$ & $\begin{array}{c}0.1430 * * * \\
(0.0000)\end{array}$ \\
\hline US shadow rt & $\begin{array}{c}0.0031 \\
(0.8217)\end{array}$ & $\begin{array}{l}0.0244 * * \\
(0.0346)\end{array}$ & $\begin{array}{c}0.0234 \\
(0.4031)\end{array}$ & $\begin{array}{c}0.0029 \\
(0.8279)\end{array}$ & $\begin{array}{l}-0.0384 \\
(0.1809)\end{array}$ & $\begin{array}{c}0.0137 \\
(0.3740)\end{array}$ & $\begin{array}{l}-0.0731 \\
(0.1077)\end{array}$ & $\begin{array}{c}0.0124 \\
(0.3523)\end{array}$ \\
\hline Observations & 9,371 & 567 & 2,520 & 5,845 & 1,787 & 7,584 & 472 & 5,373 \\
\hline Number of ifs_code & 59 & 3 & 18 & 36 & 12 & 47 & 4 & 32 \\
\hline \multicolumn{9}{|c|}{ YIELD CURVE MODEL } \\
\hline VARIABLES & All & $\begin{array}{c}\text { Pure Peg } \\
\text { to US }\end{array}$ & $\begin{array}{l}\text { Mixed ER } \\
\text { Regime }\end{array}$ & $\begin{array}{c}\text { Pure Float } \\
\text { to US }\end{array}$ & Kctrl & no Kctrl & $\begin{array}{c}\text { Pure Float } \\
\text { Kctrl }\end{array}$ & $\begin{array}{c}\text { Pure Float } \\
\text { no Kctrl }\end{array}$ \\
\hline \multicolumn{9}{|l|}{ MGE } \\
\hline US policy rt & $\begin{array}{c}0.0585 \\
(0.3441)\end{array}$ & $\begin{array}{c}0.8304 * * * \\
(0.0000)\end{array}$ & $\begin{array}{c}0.1380 \\
(0.1733)\end{array}$ & $\begin{array}{l}-0.0583 \\
(0.4473)\end{array}$ & $\begin{array}{c}0.1068 \\
(0.3569)\end{array}$ & $\begin{array}{c}0.0462 \\
(0.5224)\end{array}$ & $\begin{array}{l}-0.0615 \\
(0.7394)\end{array}$ & $\begin{array}{l}-0.0580 \\
(0.4908)\end{array}$ \\
\hline VIX & $\begin{array}{c}0.0034^{* * *} \\
(0.0093)\end{array}$ & $\begin{array}{l}0.0054^{* *} \\
(0.0422)\end{array}$ & $\begin{array}{l}0.0060 * \\
(0.0595)\end{array}$ & $\begin{array}{c}0.0020 \\
(0.1421)\end{array}$ & $\begin{array}{c}0.0060 \\
(0.1930)\end{array}$ & $\begin{array}{l}0.0027^{* *} \\
(0.0188)\end{array}$ & $\begin{array}{l}0.0044^{* *} \\
(0.0210)\end{array}$ & $\begin{array}{c}0.0017 \\
(0.2606)\end{array}$ \\
\hline L.inflation & $\begin{array}{c}0.1007^{* * *} \\
(0.0000)\end{array}$ & $\begin{array}{c}0.0014 \\
(0.7599)\end{array}$ & $\begin{array}{c}0.0749 * * * \\
(0.0003)\end{array}$ & $\begin{array}{c}0.1279 * * * \\
(0.0000)\end{array}$ & $\begin{array}{l}0.0255^{*} \\
(0.0796)\end{array}$ & $\begin{array}{c}0.1199 * * * \\
(0.0000)\end{array}$ & $\begin{array}{c}0.0132 \\
(0.3458)\end{array}$ & $\begin{array}{c}0.1422^{* * *} \\
(0.0000)\end{array}$ \\
\hline US $10 y$-pol rate & $\begin{array}{c}-0.0882^{* * *} \\
(0.0002)\end{array}$ & $\begin{array}{c}0.0379 \\
(0.2501)\end{array}$ & $\begin{array}{l}-0.0624 \\
(0.2218) \\
\end{array}$ & $\begin{array}{c}-0.1084^{* * *} \\
(0.0001)\end{array}$ & $\begin{array}{l}-0.0263 \\
(0.6545)\end{array}$ & $\begin{array}{c}-0.1040^{* * *} \\
(0.0001)\end{array}$ & $\begin{array}{l}-0.0799 \\
(0.3424)\end{array}$ & $\begin{array}{c}-0.1120 * * * \\
(0.0003)\end{array}$ \\
\hline Observations & 9,683 & 574 & 2,623 & 6,033 & 1,846 & 7,837 & 493 & 5,540 \\
\hline Number of ifs_code & 59 & 3 & 18 & 36 & 12 & 47 & 4 & 32 \\
\hline
\end{tabular}

These results prompt two natural questions. If there is short term independence, how long does it last? What explain the large heterogeneity of responses for floaters?

\section{How Long Does Monetary Policy Independence (Under Floating) Last?}

Figure 4 shows tentative evidence pointing to a horizon of about one year. Among pure floaters, the estimated response to U.S. policy rate in panel regressions starts getting marginally significant at 10 percent over about ten-month horizon, and strongly significant after one and a half years. When employing country-specific regressions, the distribution of the coefficients suggests similar patterns (see Appendix Figure 5). It is interesting to note that countries that present a higher short-term (1 month) response, also present a higher long-term response (see Appendix Figure 6). 
Figure 4. USM Panel Mean-Group Estimates and Confidence Interval (ST)

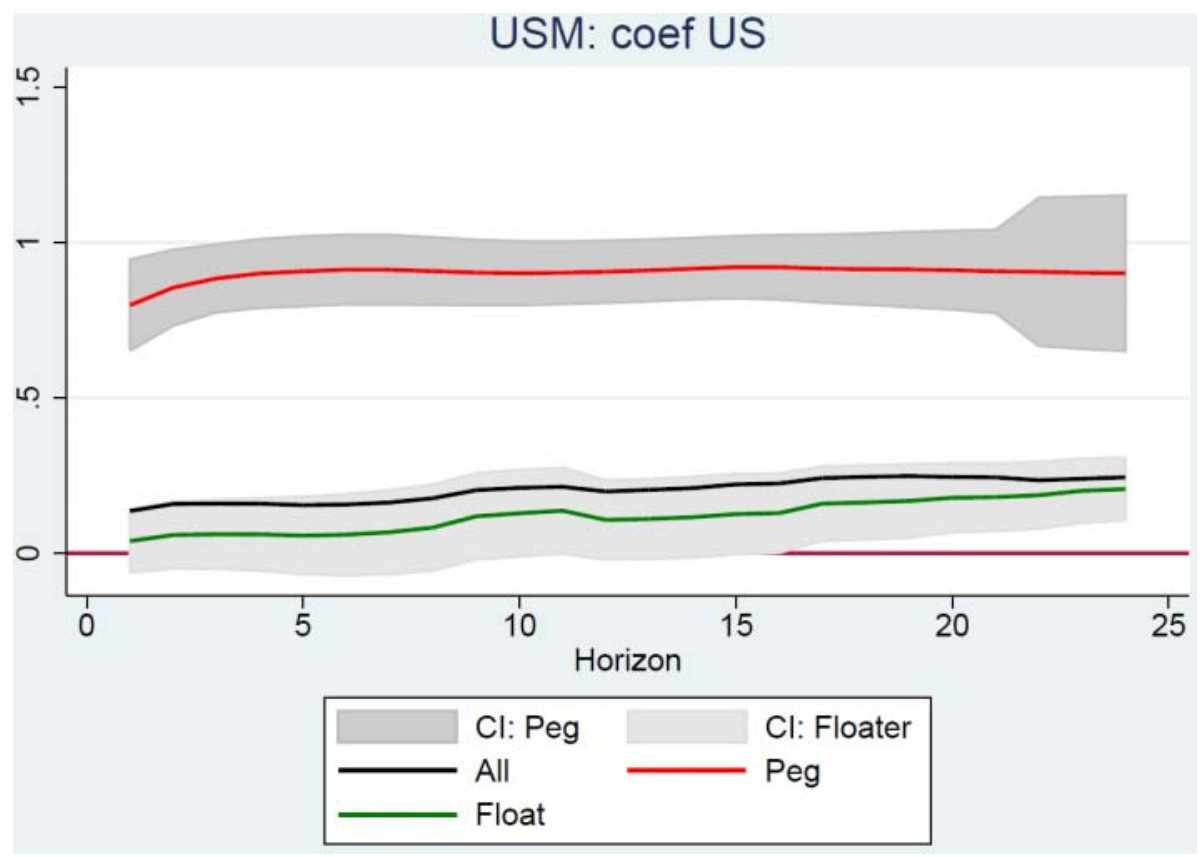

We repeat panel regressions for equation (2) using first difference (baseline ST model), twolag difference (2M), etc., up to twenty-four-lag difference (2Y). The chart plots on the horizontal axis the horizon of the lag-difference, and on the vertical axis the mean-group estimator of U.S. policy rate coefficient in the Matching Model for all countries (in black), for pure peggers (in red surrounded by 90 percent confidence interval) and for pure floaters (in green surrounded by 90 percent confidence interval).

\section{Why Not All Floaters Appear Independent?}

Even if floating allows monetary policy independence in the short term, floaters may still "choose" to include foreign interest rates in their monetary reaction function (i.e. empirically would not appear independent). In general, the different response of the policy rate of floaters to foreign rates would depend on various factors such as the degree of priority assigned to domestic objectives, the degree of tolerance for large swings in the exchange rate (fear of floating), or simply the degree of co-cyclicality of the local economy with the foreign one. The investigation of these country-specific factors and their impact on monetary policy making are the main goal of this section.

\section{Higher Priority on Domestic Objectives is Associated with Less Responsiveness to Foreign Rates}

Controlling inflation is among the major mandates of central banks all over the world, and in theory, flexible exchange rate regime enables central banks to move their policy rates away from foreign interest rates if domestic inflation steps out of the desired range. We can proxy the degree of priority of the domestic inflation objective via our inflation coefficient in the original local policy rate regression. Restricting our attention to pure floaters in our sample, we indeed find a marginally significant negative relationship between the short-run responsiveness of local policy rate to the U.S. policy rate and to domestic inflation 
(Figure 5). This suggests that floaters that care more for domestic objectives respond less to foreign rates.

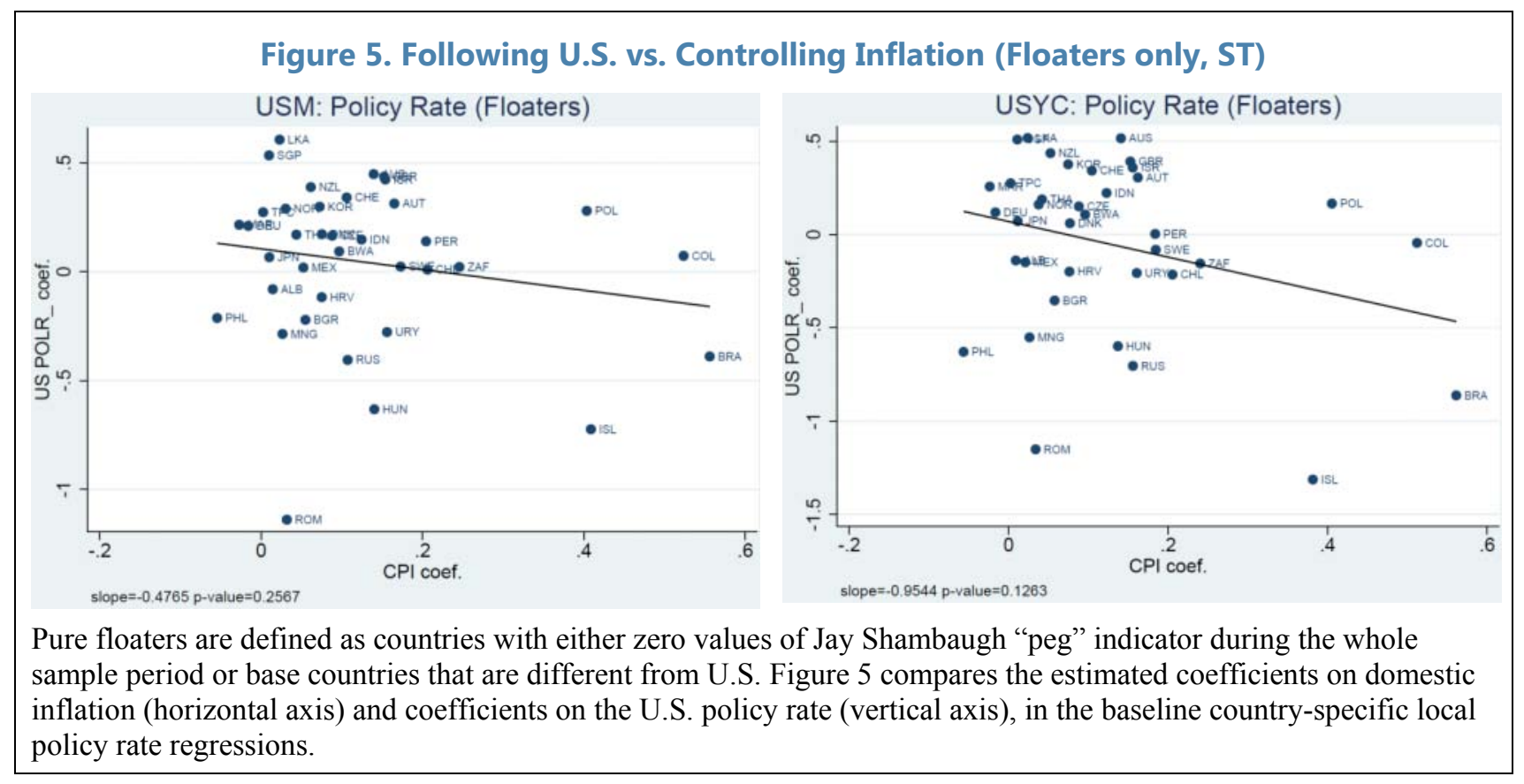

\section{Fear of Floating is Associated with More Responsiveness to Foreign Rates}

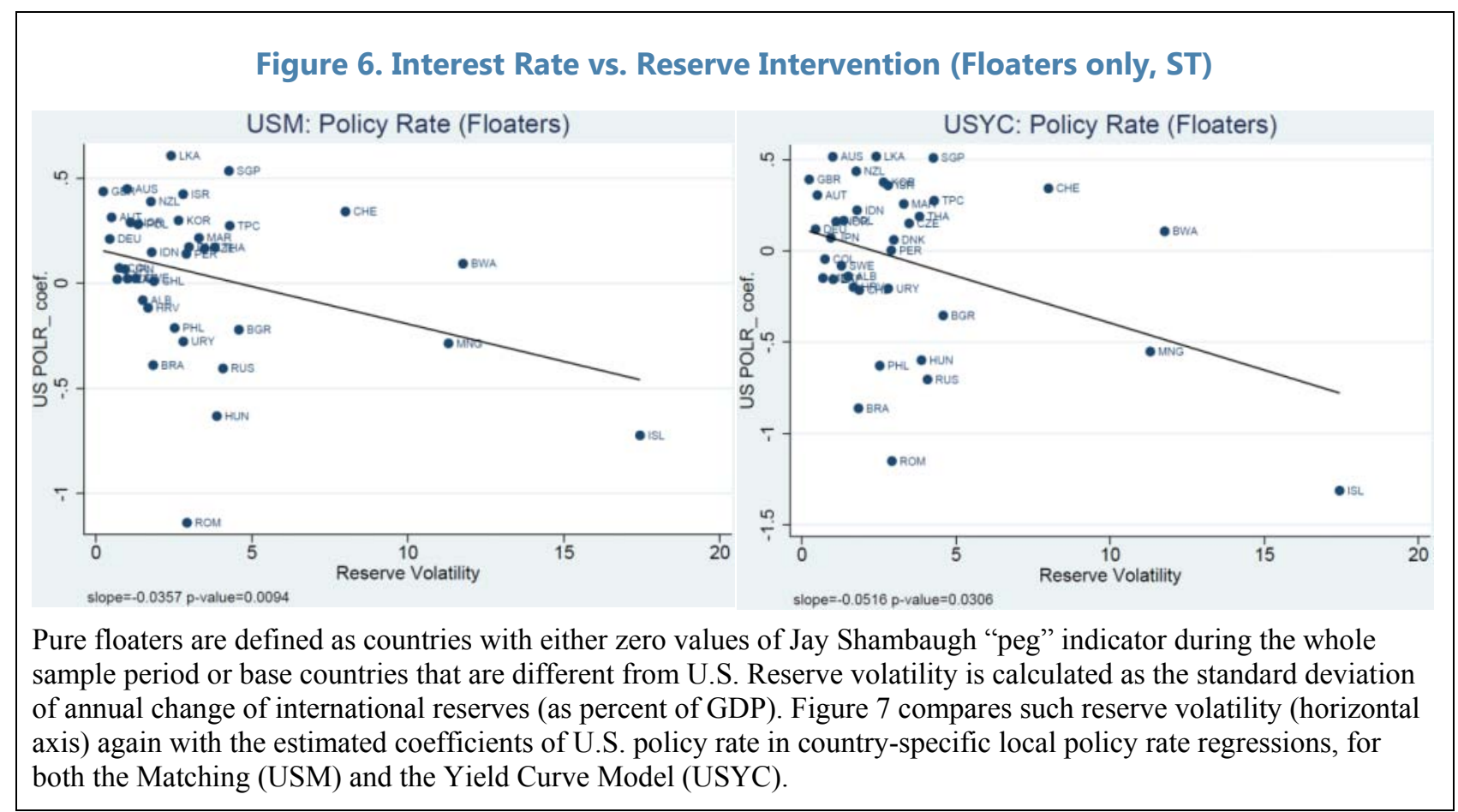

Exchange rate volatility is often a concern of central banks in setting MP, especially in emerging markets with large trade and financial linkages denominated in foreign currency. 
Moreover, countries with flexible exchange rate regime seem to treat the policy rate and international reserve as substitutable instruments to maintain exchange rate stability, since floaters with higher foreign interest rate pass-through seem to have relatively lower reserve volatility (Figure 6). Overall, this suggests that fear of floating seems to be correlated with high pass-through of U.S. interest rate changes onto domestic monetary policy.

\section{Stronger Business Cycle Synchronization is Associated with More Responsiveness to Foreign Rates}

Another possible reason for high correlation between local rates and foreign rates is that countries - especially those more integrated in the global trade and financial markets - might have similar business cycles to those of major advanced economies. In this case, adopting a similar MP would constitute the "right" policy response to domestic economic fluctuations, even if full independence is warranted by floating exchange rates.

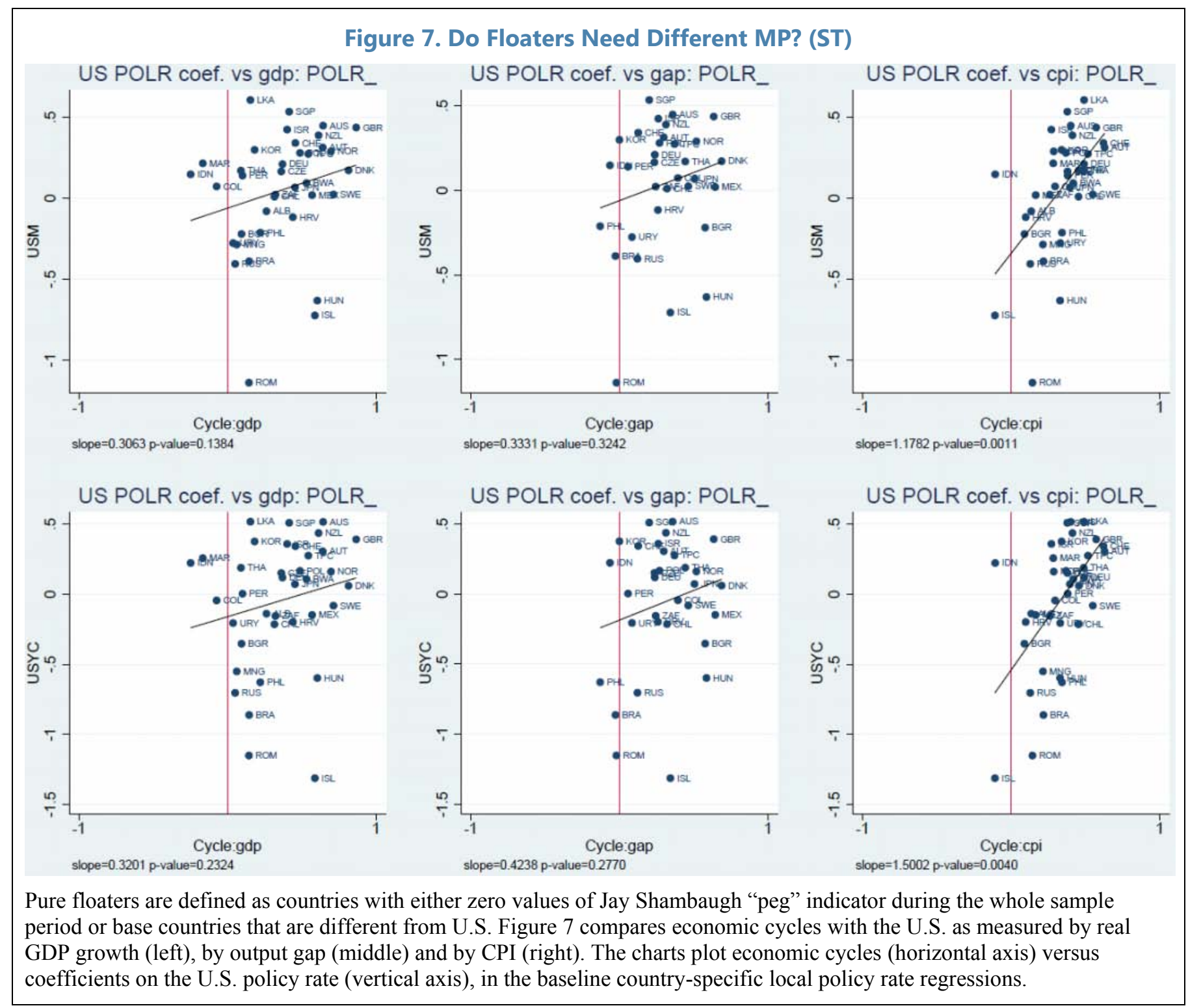


We measure the co-cyclicality of the domestic and the U.S. economy on the basis of three commonly used macro variables: the annual real GDP growth, the annual real output gap and the monthly inflation calculated as the year-on-year change in CPI. Figure 7 presents, again for floaters, three panels with these three measures of co-cyclicality on the horizontal axis, versus the usual responsiveness of local policy rate to U.S. rate on the vertical axis.

Three results are noticeable. First, all three variables suggest a positive correlation between domestic and U.S. business cycles for almost all countries in the sample (almost all dots are in the right quadrant). Therefore, it would be reasonable for floaters to conduct similar MP as the U.S. to some extent.

Second, the positive (and highly significant with respect to inflation cycle) trend line confirms the intuitive idea that floaters with more correlated business cycles with U.S. tend to have also a more correlated monetary policy.

Third, the relation between the co-cyclicality with the U.S. and the responsiveness of the local policy rate to the U.S. rate is larger for CPI, which is not surprising as inflation is generally a priority of most central banks.

When we run a small cross-country regression for the responsiveness to the U.S. policy rate on the proxies for these three arguments (importance of domestic objectives, fear of floating, and co-cyclicality with the U.S.) - controlling for the degree of capital controls, which potentially has an autonomous effect from floating on monetary policy independence - all coefficients have the expected signs (Table 2). Moreover, fear of floating and correlation with U.S. inflation appear as the most robust arguments (although the limited number of observations precludes a definitive conclusion on such ranking):

\begin{tabular}{|c|c|c|c|c|c|c|}
\hline \multicolumn{7}{|c|}{ U.S. Pol. Rate coefficient } \\
\hline & \multicolumn{3}{|c|}{ MATCHING MODEL } & \multicolumn{3}{|c|}{ YIELD CURVE MODEL } \\
\hline \multirow[t]{2}{*}{ K control } & 0.0777 & -0.3405 & 0.2843 & -0.0630 & -0.4532 & 0.2511 \\
\hline & $(0.8368)$ & $(0.3385)$ & $(0.3412)$ & (0.8769) & $(0.3417)$ & $(0.3908)$ \\
\hline \multirow[t]{2}{*}{ Own CPI coefficient } & -0.3867 & -0.0569 & -0.2963 & -0.8276 & -0.4400 & -0.7357 \\
\hline & (0.2899) & $(0.8802)$ & $(0.3301)$ & $(0.1325)$ & $(0.4526)$ & $(0.1240)$ \\
\hline \multirow[t]{2}{*}{ Reserve volatility } & $-0.0346 * *$ & $-0.0426^{* * *}$ & $-0.0168 *$ & $-0.0476 *$ & $-0.0616^{* * *}$ & $-0.0274 *$ \\
\hline & $(0.0283)$ & $(0.0040)$ & $(0.0933)$ & $(0.0503)$ & $(0.0032)$ & $(0.0778)$ \\
\hline \multirow[t]{2}{*}{ Corr. with US: GDP } & 0.3088 & & & 0.2440 & & \\
\hline & $(0.2458)$ & & & $(0.4112)$ & & \\
\hline \multirow[t]{2}{*}{ Corr. with US: Output G } & & 0.2651 & & & 0.3059 & \\
\hline & & $(0.4605)$ & & & $(0.4613)$ & \\
\hline \multirow[t]{2}{*}{ Corr. with US: CPI } & & & $1.1636^{* *}$ & & & $1.3477^{* *}$ \\
\hline & & & $(0.0136)$ & & & $(0.0146)$ \\
\hline Observations & 35 & 31 & 35 & 35 & 31 & 35 \\
\hline Adjusted R-square & 0.0586 & 0.0781 & 0.2816 & 0.1329 & 0.1938 & 0.3517 \\
\hline
\end{tabular}




\section{Do Foreign Rates Generate the Equivalent of a Greenspan Conundrum for Central Bankers?}

The transmission from foreign rates to domestic rates creates a potential conundrum for central banks, as it makes more difficult to control their local rate curve and fully control the monetary transmission mechanism. Greenspan had a similar problem in 2004-06 when longterm rates failed to increase while he was raising the policy rate (unlike in the past, when they always responded ${ }^{10}$ ), and termed this situation a "conundrum" during a congressional testimony in 2005 . Here we wonder more broadly about the ability of countries to influence the whole curve, not just the long end, also because often in emerging markets short-term and medium-term rates play a bigger role in the monetary transmission mechanism than long rates. The question arises from the strong influence of foreign variables on the local rates that we have documented in previous sections (see for example Figure 2).

Indeed, this question relates very closely to a mirror question: is the effect of foreign interest rates on the local curve occurring via its effect on the local policy rate? If so, then central bankers have full control of their yield curve, and the response of the local curve to foreign rate is simply the reflection of the choice of the monetary authorities to follow foreign rates coupled with their ability to influence local rates. If not, then there is a direct influence of foreign rates on local rates which diminishes the ability of central bankers to influence the local curve.

To study the transmission of foreign interest rate shocks into the domestic yield curve, we modify our baseline models to include the local policy rate in the non-policy rate regressions. Figure 8 presents the estimated effects across the curve with the last column showing the newly added estimates related to the local policy rate. Comparing it with Figure 2, the following observations stand out:

- The short end of the local yield curve (the interbank rate and the bank deposit and lending rates) does not respond directly to the U.S. policy rate (left panels). Instead, the local policy rate has a substantial impact on these rates (right panels). Hence their association with foreign rate is indirect, via the channel of the local policy rate;

- The inclusion of the local policy rate does not significantly alter the medium response of the local interbank rate and bank deposit and lending rates to other determinants, i.e. the U.S. shadow rate or the U.S. yield curve, financial market uncertainty (VIX), and domestic inflation (middle three panels);

- The 2-year and 10-year government bond yields coefficients in Figure 8 do not show a big difference from Figure 2, meaning that local policy rate has limited impact on the long end of the local yield curve, and most pass-through from the U.S. rates is the result of a direct effect. Appendix Figure 7 (which shows that the response of local

\footnotetext{
${ }^{10}$ Our Figure 2 shows that U.S. long term rates respond one to one to the policy rate on average, which implies that on average, i.e. over most of the sample, there was no "Greenspan conundrum" in the U.S.
} 
LT rates to U.S. LT rates - on the vertical axis - is larger than the response to local policy rates - on the horizontal axis - i.e. dots are above the 45 degree line) confirms such result and shows that Greenspan conundrum also holds for most countries in our sample (mainly EMs). This is likely to be due to the strong global financial integration.

- These results hold also when considering the long-term responses of the local rates to U.S. rates and to the local policy rate. ${ }^{11}$

Hence, central banks face a conundrum equivalent to the one of Greenspan in 2004-06 (limited ability to control the long term rates), but such a conundrum does not extend to short-term rates, over which they can exert significant influence.

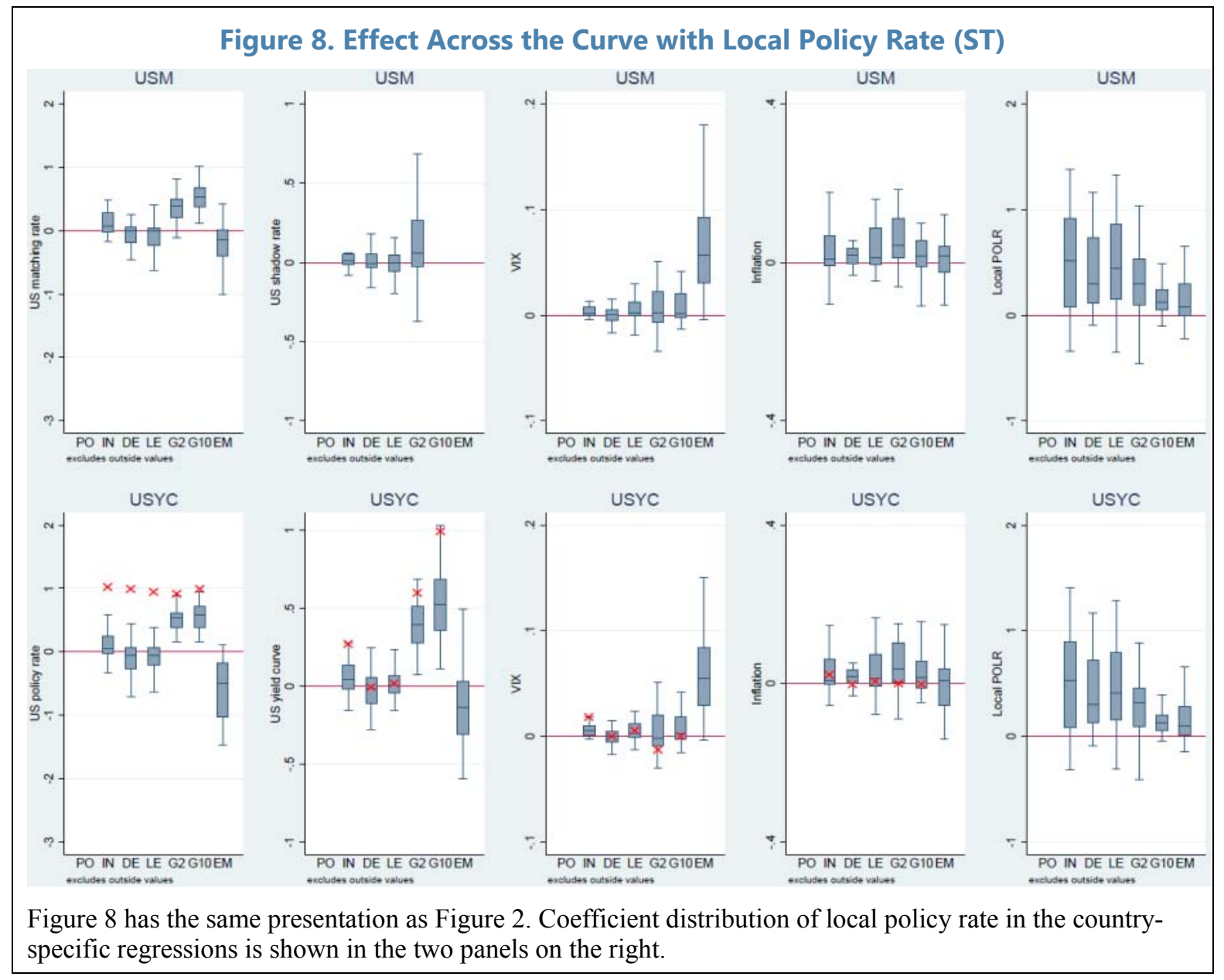

This finding is quite meaningful for the MP independence debate in the sense that it establishes the linkage between policy rate independence and local short-term rates independence. In other words, if countries manage to maintain a policy rate independent from foreign influences, they gain control of the short end of their local currency rate curve.

${ }^{11}$ Regressions in level available upon request. 
This relates closely to Rey (2014) argument that a global credit cycle impedes central banks from operating their monetary transmission mechanism. Our results suggest that central banks retain the control of their monetary transmission mechanism via the short end of the curve (as local policy rates appear to be the conduit for the transmission of the global credit cycle) but not at the long end of the curve (where a "Greenspan conundrum" applies).

\section{Robustness Checks}

\section{A. Do Global Factors and Exchange Rate Alter The Picture?}

One possible issue that might distort our conclusion is the common cycle in the global economy. If both the U.S. and local monetary authorities respond in a similar way to the global cycle, our estimate of U.S. rate pass-through might be biased upward. To study whether this is indeed the case, we augment the baseline models by adding the following variables: (1) oil price inflation; (2) global inflation calculated as the first principle component of CPI inflation across our sample of countries; and (3) global output proxied by the first principle component of growth in industrial production across our sample.

On top of the global factors introduced above, we also add the year-on-year change of the nominal effective exchange rate (NEER) to reflect the possibility that monetary authorities may react to the change in the exchange rate when choosing their policy rate. Finally we add the local policy rate, in order to check robustness also versus the arguments presented in section IV.D (see Appendix Figure 8). ${ }^{12}$

The estimated impact of U.S. policy rate on local policy rate is robust to the inclusion of global factors and change in NEER (left panels, first column). Again as discussed in section IV.D, short-term non-bank rates are more prone to indirect pass-through from U.S., while medium-term and long-term rates display much larger direct pass-through. Responsiveness of local interest rates to the VIX index does not seem to be affected by the presence of global variables and NEER.

Interestingly, the local interest rates respond positively to global inflation cycle, and —quite consistently - the estimated inflation coefficient in the local policy rate regression becomes smaller. This suggests that the influence of the global cycle was captured in the baseline regression by the response to inflation, not - as one might have feared - from the response to the U.S. rates. The global industrial production and international oil price inflation on average have little impact on local interest rate, except for the emerging market sovereign spread, in which case they impose negative influence. Local currency interest rates in the average country in our analysis also shows no reaction to NEER changes, though NEER depreciation tends to be negatively related to the sovereign spread.

Since responsiveness of local policy rate to U.S. policy rate remains roughly the same despite the inclusion of global factors and exchange rate risks, our previous discussion on the trilemma remains robust.

\footnotetext{
${ }^{12}$ Results without the local policy rates are available upon request.
} 


\section{B. Baseline versus Error-Correction Model (ECM)}

The highly persistent interest rates are consistent with unit roots and cointegration. ${ }^{13}$ For robustness, we estimate an error-correction model widely adopted in the literature when the underlying data show long-term trend. Following Pesaran's Pooled Mean-Group approach, we assume that individual countries share the same long-run coefficients in the panel regression, while the short-run coefficients as well as the converging speed can differ.

$$
\begin{aligned}
\Delta i_{c, t}^{j}= & \alpha^{j, c}+\delta^{j, c} \cdot \Delta i_{c, t-1}^{j}+\beta^{j, c} \cdot \Delta \boldsymbol{I}_{u s, t-1}^{j}+\gamma^{j, c} \cdot \Delta V I X_{t-1}+\theta^{j, c} \cdot \Delta \boldsymbol{X}_{c, t-1}^{j} \\
& +\xi^{j, c}\left[i_{c, t-1}^{j}-\bar{\beta}^{j} \cdot \boldsymbol{I}_{u s, t-1}^{j}-\bar{\gamma}^{j} \cdot V I X_{t-1}-\bar{\theta}^{j} \cdot \boldsymbol{X}_{c, t-1}^{j}\right]+\varepsilon_{c, t}^{j}
\end{aligned}
$$

As can be seen in Figure 9, the coefficients estimated in our baseline model are consistent with the short term coefficients implied by the corresponding ECM. The country-specific converging speed parameter $(\xi)$ ranges from 0 to -0.15 , with an average of about -0.05 , which implies a half-life of deviations of about 1 year.

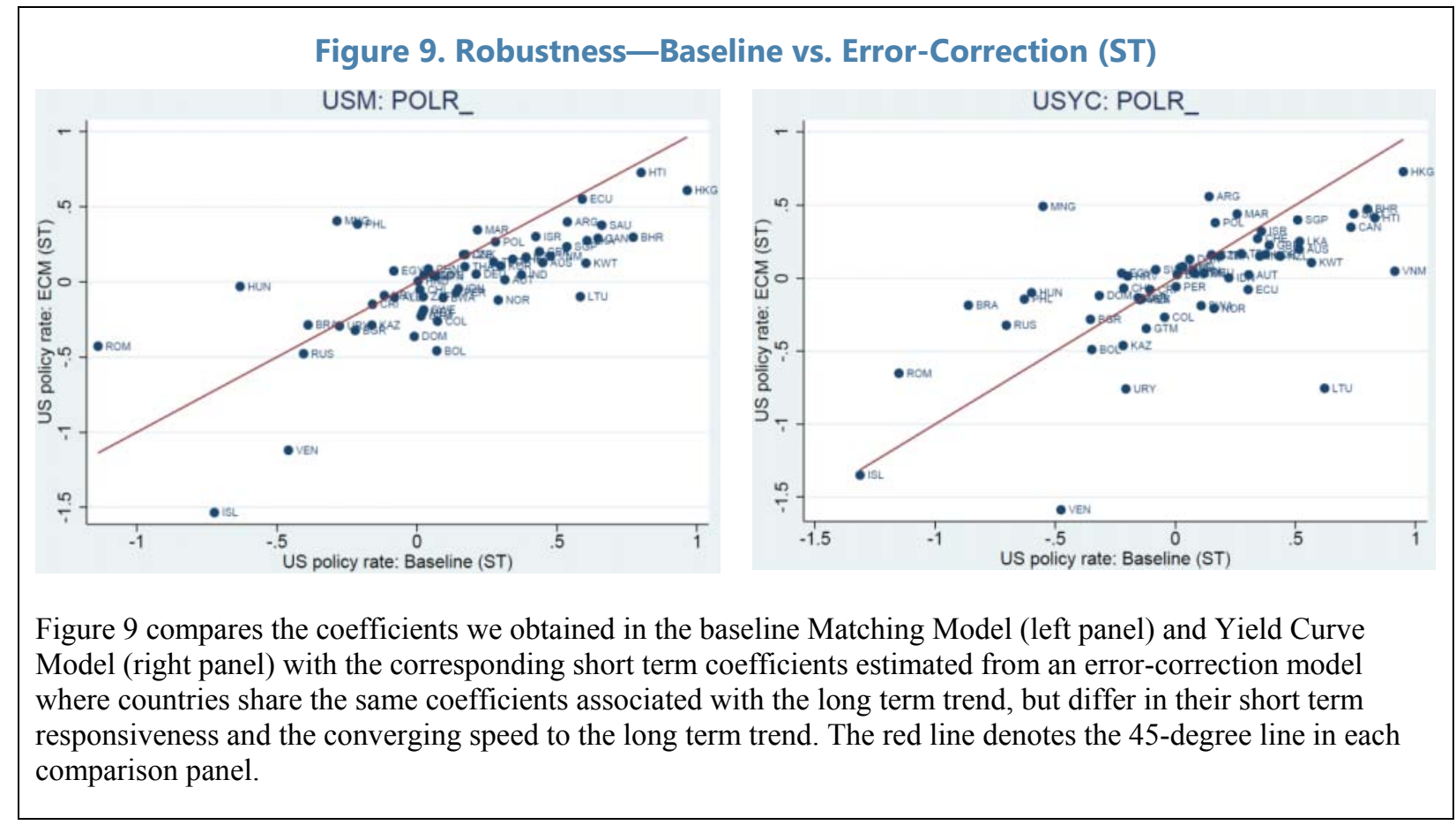

\section{Adding Output Gap}

The output gap, a standard component in the Taylor Rule estimation, does not appear in our baseline models because a robust measure for real GDP at monthly frequency is difficult to

\footnotetext{
${ }^{13} \mathrm{We}$ fail to reject the unit root hypothesis for a large number of countries in the sample with country-bycountry test at usual significance level. Both baseline Matching Model and Yield Curve strongly reject the nocointegration null hypothesis in the ECM panel cointegration test.
} 
obtain for most countries in our sample. In this section, for robustness concern, we smoothly splice the annual output gap data retrieved from the World Economic Outlook (WEO) database and add the constructed monthly series to the regressions. A twelve-month lag is imposed for the output gap to reduce potential endogeneity problems, which are exacerbated by the fact that original data is annual.

In the country-specific regressions, the output gap indeed has a significant coefficient for most countries and, according to the adjusted R-squared, helps improve the fit of the models. However, as shown in Figure 10, adding output gap does not significantly change the response of the local interest rate to the U.S. interest rate (the local policy rate regression is used as an example), as well as to VIX (not shown), in the baseline models. The same results hold in the augmented models.

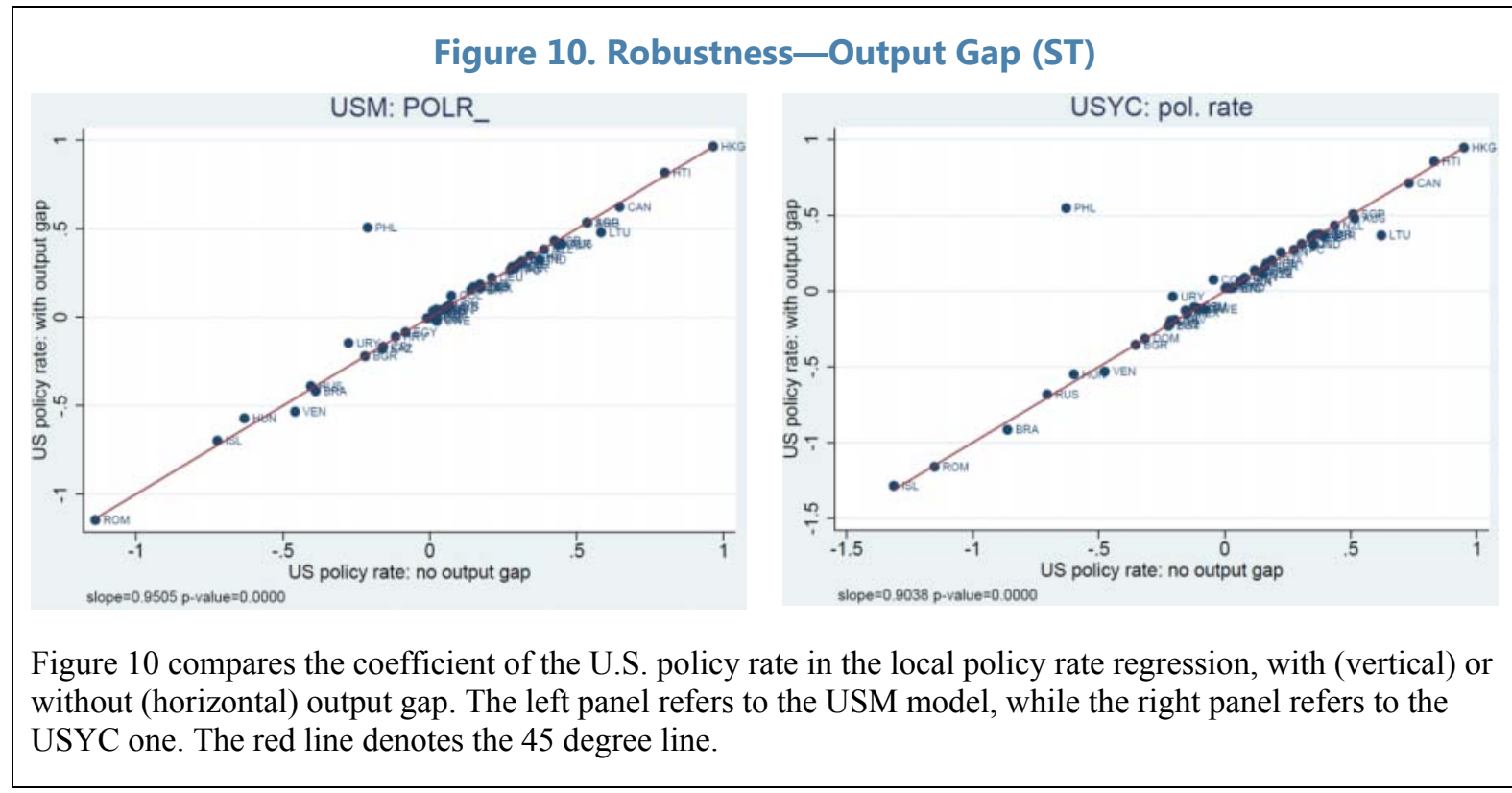

\section{Structural Change during the Recent Global Crisis}

As discussed above, the presence of a zero lower bound is addressed by introducing the shadow interest rate in the Matching Model and the U.S. curve in the Yield Curve Model. However, one may nonetheless wonder if restricting the sample to pre-crisis period would affect the results, as post-2009 the Fed switched to unconventional monetary policy. Cutting the sample at December 2008 offers a robustness check (although it somewhat restricts the number of eligible countries). The resulting U.S. policy rate coefficients in the local policy rate regression are plotted in Figure 11 against their counterparts in the full-sample baseline regressions. For both the Matching Model and the Yield Curve Model, the pre-2009 sample shows no systemic bias of the U.S. policy rate pass-through estimated from the full sample. Similar results hold for the VIX coefficients. 

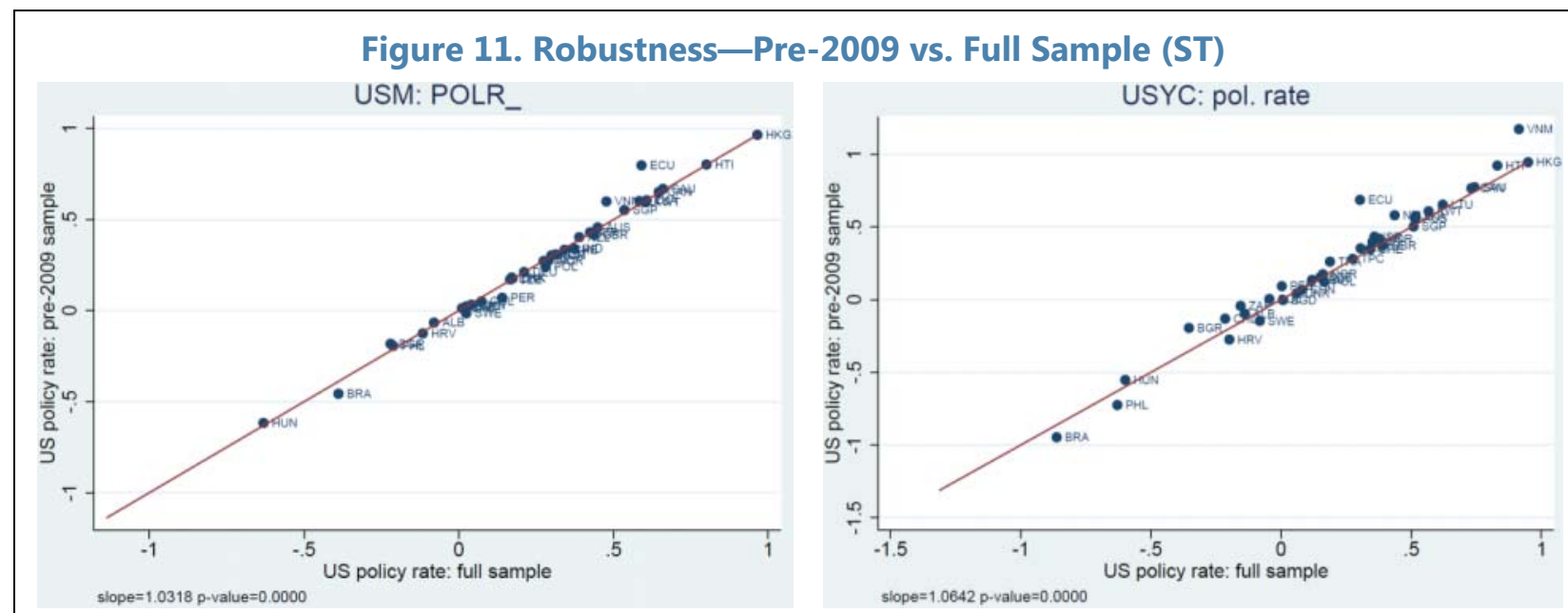

Figure 11 compares the coefficient of the U.S. policy rate in the local policy rate regression, with the full sample (horizontal) and the pre-2009 sample (vertical). The left panel refers to the USM model, while the right panel refers to the USYC one. The red line denotes the 45 degree line.

\section{Conclusions}

This paper re-evaluates the classical policy trilemma in international economics among exchange rate stability, capital mobility and independent monetary policy. We inspect the distribution of coefficients resulting from country-by-country regressions of local interest rates on both domestic and foreign factors. Not surprisingly, given the more and more integrated global financial market, we find that foreign factors, such as the U.S. interest rate and the VIX index, have strong influence on local interest rates, both in the short run and in the long run, though with large country heterogeneity. In particular, the local interest rates in general show a positive response to U.S. rates, and such a response gets stronger for longer maturities. VIX also has a positive impact on most countries' local interest rates, and such an impact is especially strong for the emerging market sovereign spread (EMBI).

Zooming in on local policy rates and the dilemma-trilemma policy debate on monetary policy independence, our analysis suggests several interesting results concerning interest rate independence in the short run.

First, the exchange rate regime matters for interest rate independence, while capital controls seem to matter for peggers. Peggers without capital controls follow closely the U.S. MP, while peggers with heavy capital controls show much less U.S. influence (for instance, see countries at the bottom-left of Appendix Figure 9, which shows the usual coefficient of the local policy rate on the U.S. policy rate versus a dummy for floating versus the U.S.; darker colors indicates a higher degree of capital controls). Floaters, on the other hand, respond on average much less to U.S. policy rate movements in the short term.

Second, the monetary policy "independence" bought by floating seems to last about one year.

Third, individual floaters' responses appear to be highly heterogeneous (some floaters' policy rates seem to follow the U.S. rate quite closely and others do not). Such heterogeneous response seems to be related to policy choices, which validates such heterogeneity as a measure of independence. More precisely, floaters tend to allow more pass-through of U.S. 
policy rate into the local policy rate if: (1) their business cycles are more correlated with that of U.S. (particularly for inflation); (2) they exhibit stronger fear of floating (for example, display smaller volatility of official reserves); and (3) they care relatively less about changes in domestic inflation.

Hence, we agree with Obstfeld (2015), in the sense that a floating exchange rate regime seems to give countries more flexibility in tailoring their policy rate to domestic needs, at least in the short run. In this respect, MP independence is the ability of the monetary authority to pursue a range of goals, rather than simply the lack of influence from foreign factors. And the relation of the heterogeneous responses of the floaters with the underlying diverse policy objectives is indicative of MP independence.

A related issue concerns the transmission channel through which the foreign interest rate changes spill over to the domestic financial market. This issue is of particular relevance to central banks, as they wonder about their ability to influence their local rate curve in the context of a strongly integrated global capital market. In a sense, this issue is about the independence of their monetary transmission channel and is much broader than their ability to independently set local policy rate. Do central banks experience a sort of Greenspan conundrum? And if so, in which segment of the local rate curve? Is the global credit cycle discussed by Rey (2014) leaving central banks unable to influence their local rate curve?

In this respect, a third key result of this paper is that the local policy rate is the major channel through which foreign rates influence the short end of the local interest rate curve (up to twoyear maturity), while the long end of the curve (ten-year) is mainly affected by the direct effect of U.S. long term interest rates, with only a small pass-through from the local policy rate. Therefore, countries that manage to maintain a relatively independent MP are able to effectively pass on the desired policy to the short end of the local rate curve. Long term rates, however, are more prone to foreign influences, suggesting the presence of a "Greenspan conundrum" for most central bankers at the long end of the curve, and consistently with the Rey (2014) study on credit cycle and mortgage rates in a few advanced economies, and standard arguments related to a strong global financial integration.

Our results are robust to several model variants, including the control for global factors and exchange rate movements. Going forward, it would be appropriate to study the time dimension of U.S. interest rate pass-through and its relation with the business cycle, i.e. whether countries choose a different response to foreign rates over time, depending for example on the current relation of their economic cycle to the foreign one. It would also be valuable to extend the analysis to spillovers arising from other advanced economies than the U.S. (in light of the recent effects of European events on global rates), within the context of alternative dynamic specifications. 


\section{References}

Aizenman, Joshua, Menzie D. Chinn, and Hiro Ito, 2015, "Monetary Policy Spillovers and the Trilemma in the New Normal: Periphery Country Sensitivity to Core Country Conditions," NBER Working Paper No. 21128 (Cambridge, Massachusetts: MIT Press).

, 2010, "The Emerging Global Financial Architecture: Tracing and Evaluating New Patterns Of The Trilemma Configuration," Journal of International Money and Finance, Vol. 29, pp. 615-641.

Arora, Vivek, and Martin Cerisola, 2001, "How Does U.S. Monetary Policy Influence Sovereign Spreads in Emerging Markets?," Staff Papers, International Monetary Fund, Vol. 48, No. 3, pp.474-98.

Bruno, Valentina, Hyun Song Shin, 2015, "Capital Flows and the Risk-Taking Channel of Monetary Policy," Journal of Monetary Economics, Vol. 71, pp. 11-132.

Chen, Jiaqian, Tommaso Mancini-Griffoli and Ratna Sahay, 2014, "Spillovers from United States Monetary Policy on Emerging Markets: Different This Time?," IMF Working Paper 14/240 (Washington: International Monetary Fund).

Davis, J. Scott, 2014, "Inflation Targeting and the Anchoring of Inflation Expectations: Cross-Country Evidence from Consensus Forecasts," Federal Reserve Bank of Dallas, Globalization and Monetary Policy Institute, Working Paper No. 174.

Ebeke, Christian, Annette Kyobe, 2014, "Global Financial Spillovers to Emerging Market Sovereign Bond Market: The Role of Foreign Participation and The Investor Base," IMF, Republic of Poland, Selected Issues.

Edwards, Sebastian, 2015, "Monetary Policy Independence Under Flexible Exchange Rates: An Illusion?,” NBER Working Paper 2089321128 (Cambridge, Massachusetts: MIT Press).

Frankel, Jeffrey, Sergio L. Schmukler and Luis Serven, 2004, “Global transmission of interest rates: monetary independence and currency regime," Journal of International Money and Finance.

Henriksen, Espen, Finn E. Kydland and Roman Sustek, 2013, “Globally correlated nominal fluctuations," Journal of Monetary Economics, Vol. 60, pp. 613-631.

Internation Monetary Fund, 2014, Spillover Report (June).

Internation Monetary Fund, Regional Economic Outlook, 2014, Western Hemisphere (April).

Klein, Michael W., 2013, “Capital Controls: Gates Versus Walls,” VOX (January). 
Klein, Michael W., and Jay C. Shambough, 2013, "Rounding the Corners of the Policy Trilemma: Sources of Monetary Policy Autonomy,” NBER Working Paper 19461 (Cambridge, Massachusetts: MIT Press).

Klein, Michael W., and Jay C. Shambough, 2013, "Is There a Dilemma with the Trilemma," VOX.

Krippner, Leo, 2013, “A Tractable Framework for Zero Lower Bound Gaussian Term Structure Models," Reserve Bank of New Zealand Working Paper.

Lombardi, Marco and Feng Zhu, 2014, "A Shadow Policy Rate to Calibrate U.S. Monetary Policy at the Zero Lower Bound,” BIS Working Paper (Basel: Bank for International Settlements).

Obstfeld, Maurice, 2015, "Trilemmas and Tradeoffs: Living with Financial Globalization," BIS working paper.

Obstfeld, Maurice, Jay C. Shambaugh, and Alan M. Taylor, 2005, "The trilemma in history: Tradeoffs Among Exchange Rates, Monetary Policies, and Capital Mobility," The Review of Economics and Statistics, No. 87(3): pp. 423 - 438.

Ostry, Jonathan D., Atish R. Ghosh, and Marcos Chamon, 2012, "Two Targets, Two Instruments: Monetary and Exchange Rate Policies in Emerging Market Economies," IMF Staff Discussion Note, SDN/12/01.

Quinn, Dennis P., 1997, “The Correlates of Change in International Financial Regulation,” American Political Science Review, Vol. 91, pp. 531-51.

Quinn, Dennis P. and A. Maria Toyoda, 2008, "Does Capital Account Liberalization Lead to Economic Growth?," Review of Financial Studies, Vol. 21(3): pp. 1403-49.

Rey, Helene, 2013, "Dilemma not Trilemma: The Global Financial Cycle and Monetary Policy Independence," Working Paper.

Rey, Helene, 2014, “The International Credit Channel and Monetary Autonomy," IMF $15^{\text {th }}$ Jacques Polak Annual Research Conference, Mundell-Fleming Lecture, No. 13 (November).

Rogers, John H., Chiara Scotti, Jonathan H. Wright, 2014, "Evaluating Asset-Market Effect of Unconventional Monetary Policy: A Multi-Country Review," Economic Policy pp.749-799.

Sahay, Ratna, Vivek Arora, Thanos Arvanitis, Hamid Faruqee, Papa N'Diaye, Tommaso Mancini-Griffoli and an IMF Team, 2014, "Emerging Market Volatility: Lessons from the Taper Tantrum," IMF Staff Discussion Note, SDN/14/09.

Shambaugh, Jay, 2004, “The Effects of Fixed Exchange Rates on Monetary Policy," The Quarterly Journal of Economics. 
Taylor, John B., 1993, “Discretion Versus Policy Rules in Practice,” Carnegie-Rochester Conference Series on Public Policy No. 39, pp. 195-214.

Wu, Jing Cynthis, Fan Dora Xia, 2014, "Measuring the Macroeconomic Impact of Monetary Policy at the Zero Lower Bound," Working Paper. 


\section{Appendix. Additional Material}
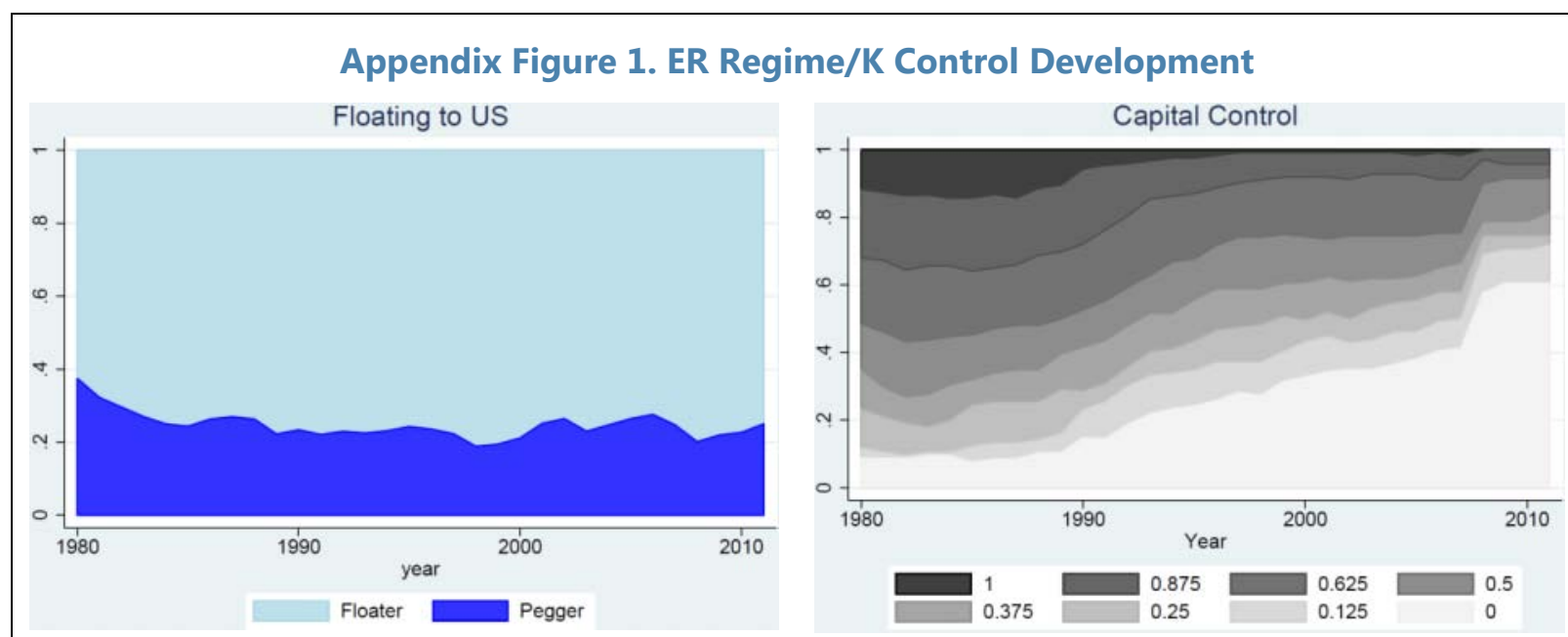

Left: The exchange rate regime classification (a zero-one dummy) follows Jay Shambaugh (2004) index of whether a country pegs to a base country (U.S. in our analysis) or not (based on actual behavior rather than declared status). The share of countries that peg to U.S. or float relative to U.S. is plotted in the chart.

Right: The capital controls measure is the Quinn-Toyoda index (Quinn 1997, and Quinn and Toyoda, 2008, normalized to be between 0 and 1), where higher value indicates more control (darker color). Shares of countries are shown in the chart. 


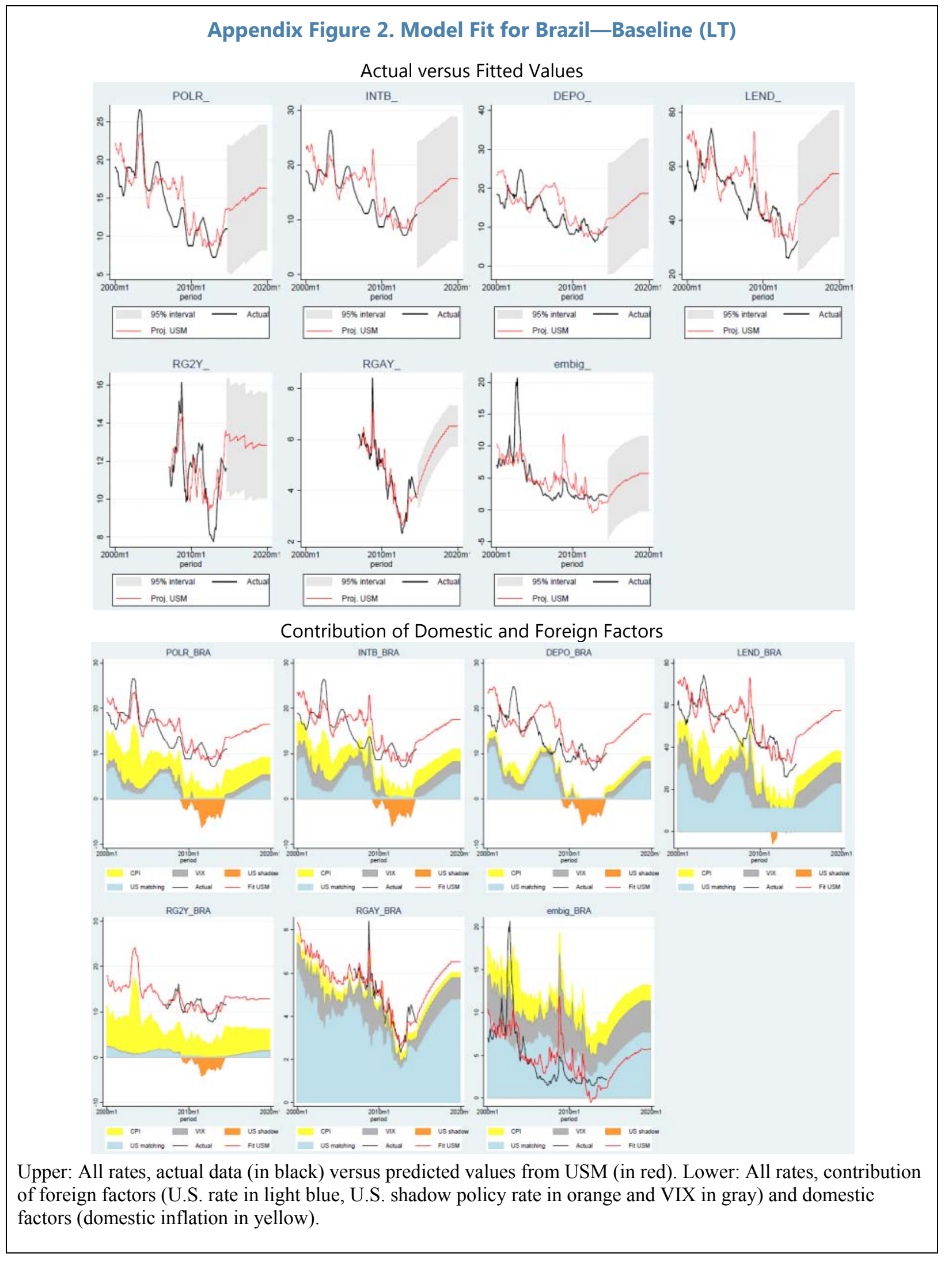




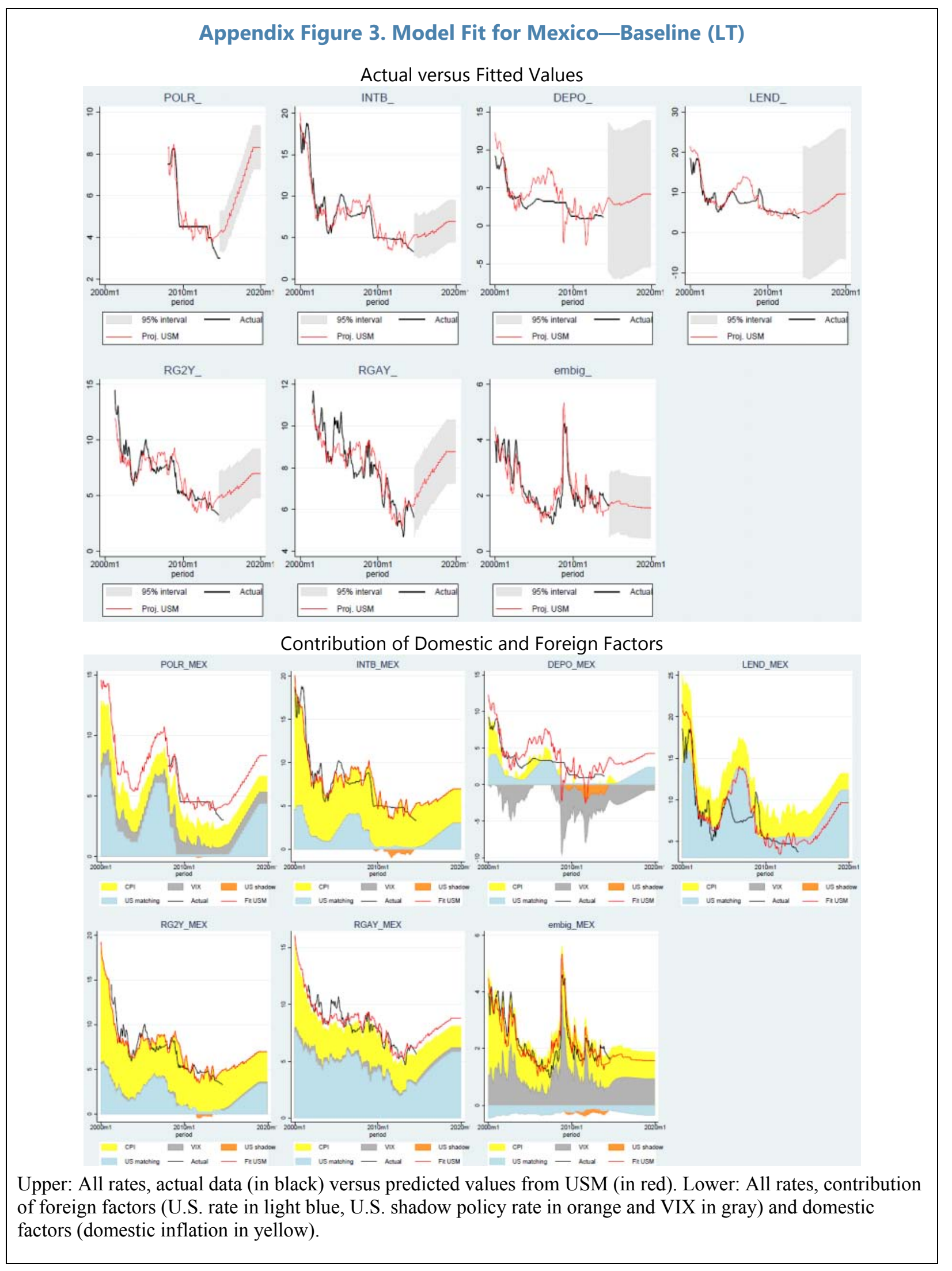


Appendix Figure 4. Floating Allow More Reaction to Domestic Inflation (ST)
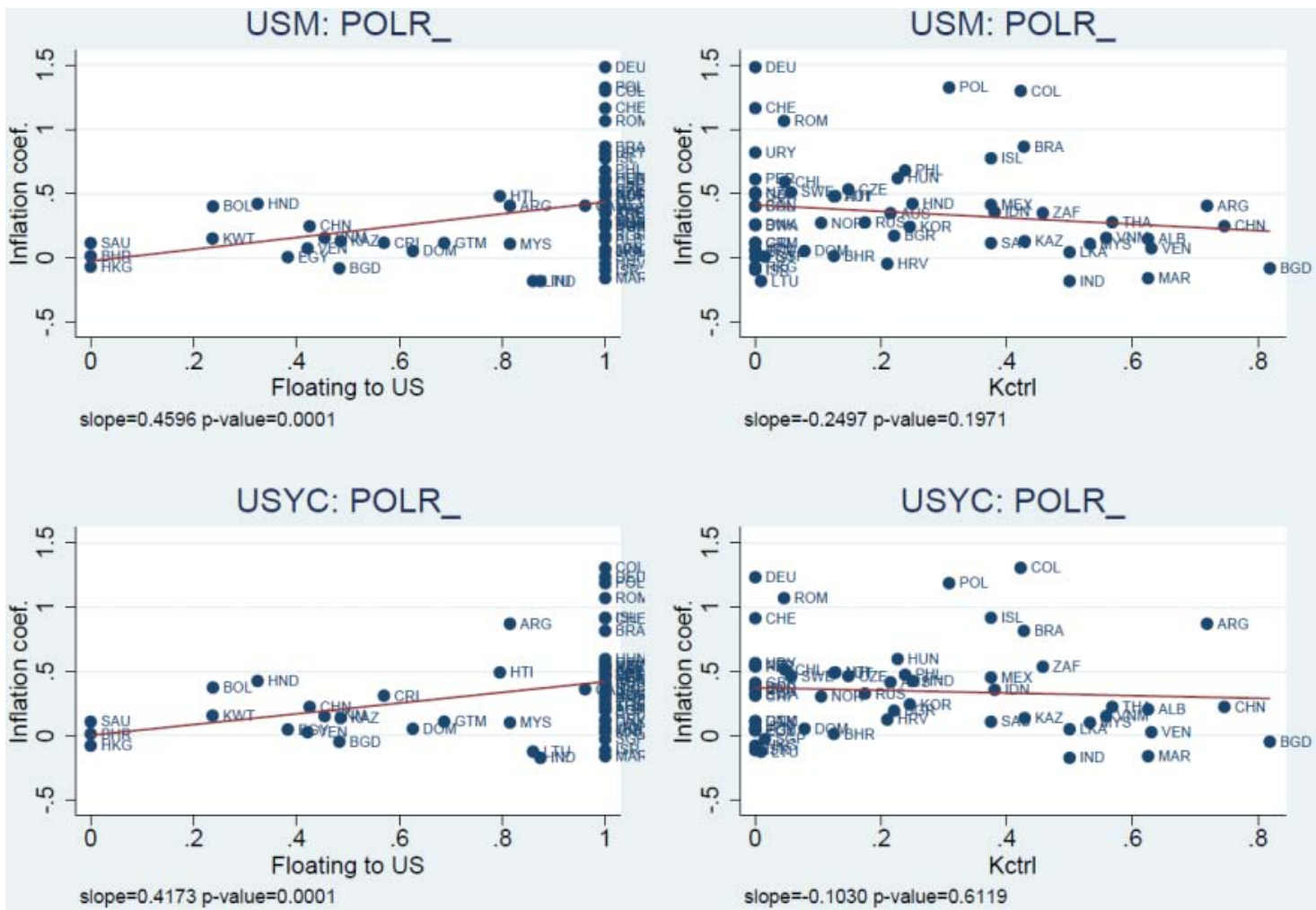

Left: CPI coefficients in local policy rate regression against exchange rate regime (floating to U.S.), Matching Model in upper panel, Yield Curve Model in lower panel. Floaters only.

Right: CPI coefficients in local policy rate regression against degree of capital control (larger value means more control), Matching Model in upper panel, Yield Curve Model in lower panel. Floaters only.
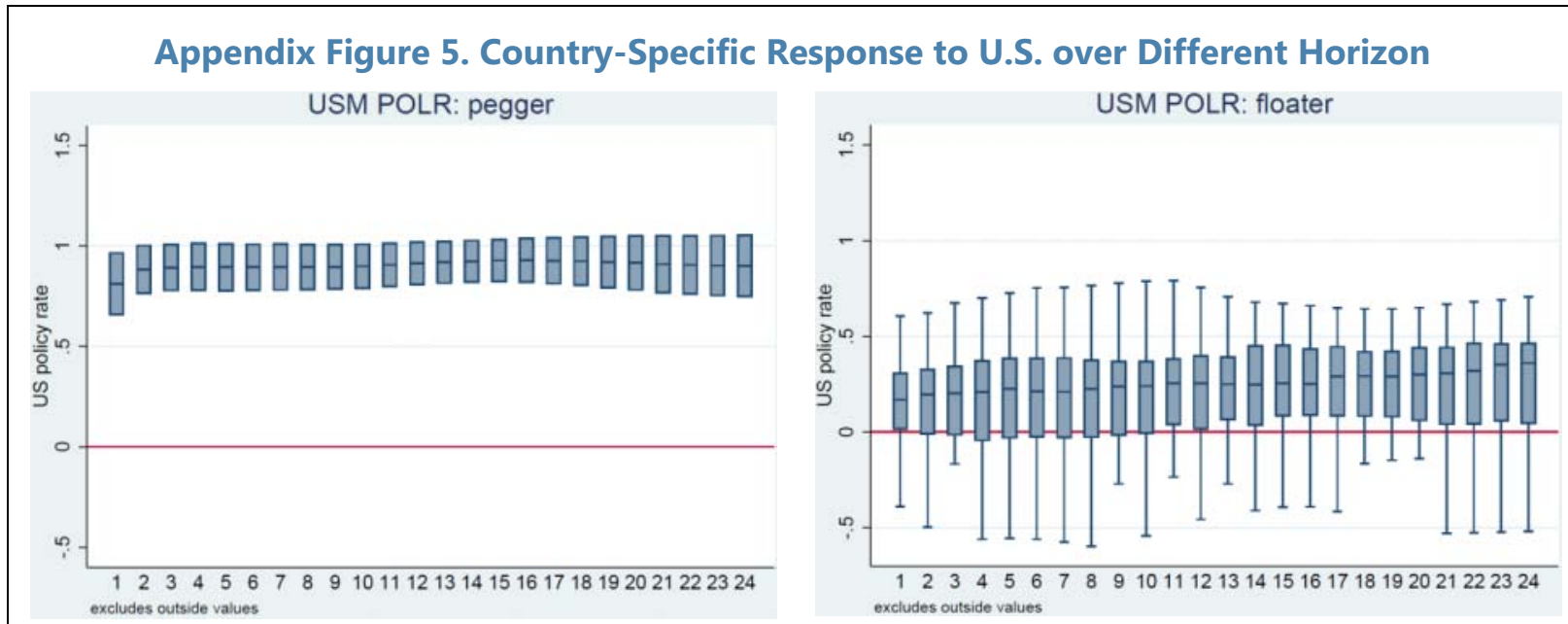

Distribution of country-specific U.S. policy rate coefficients in local policy rate regression with time horizon varies from one-month difference to two-year difference. Pure peggers are on the left, while pure floaters are on the right. 


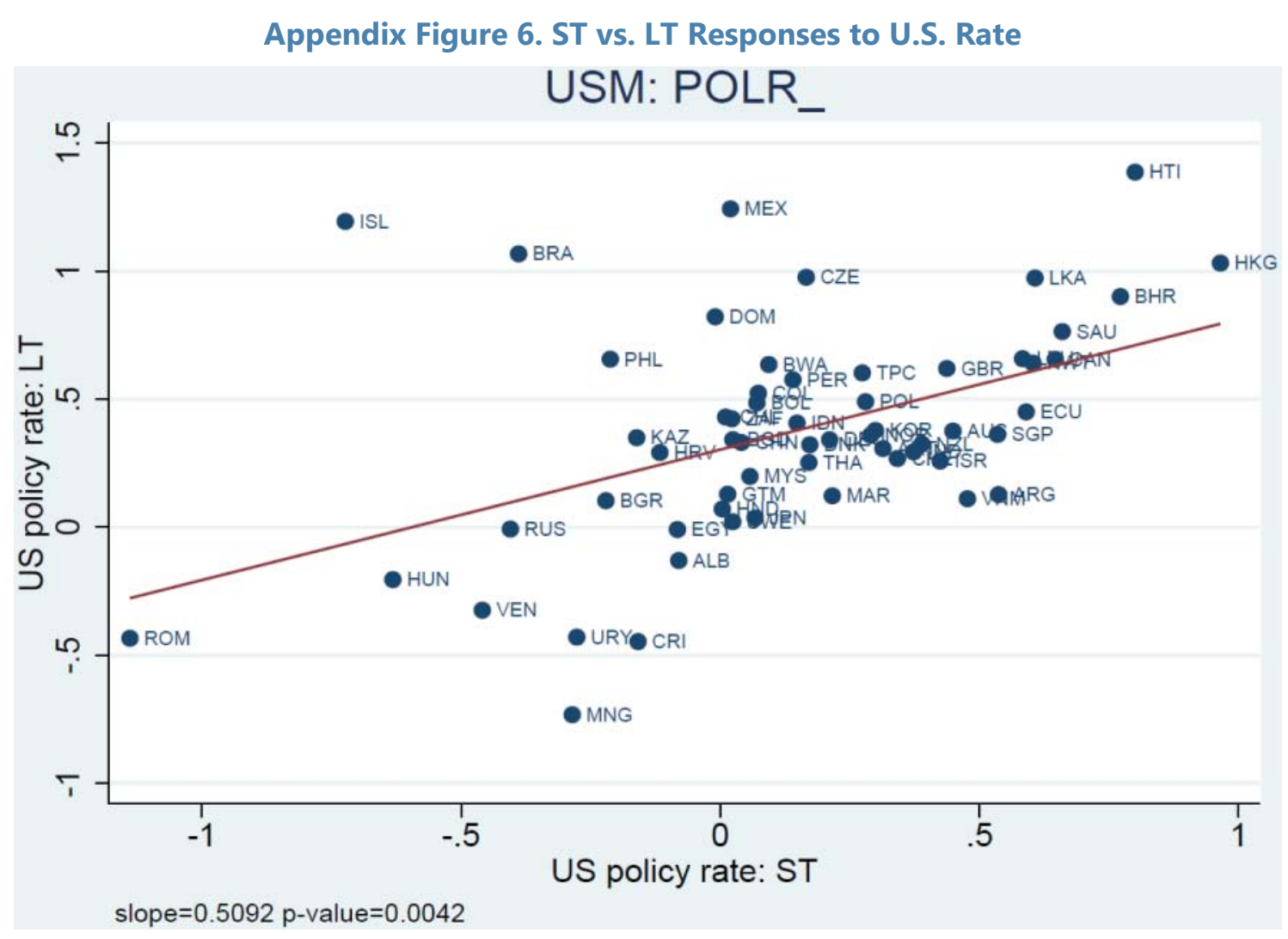

The Matching Model short-term and long-term U.S. policy rate coefficients from the local policy rate regression are compared.
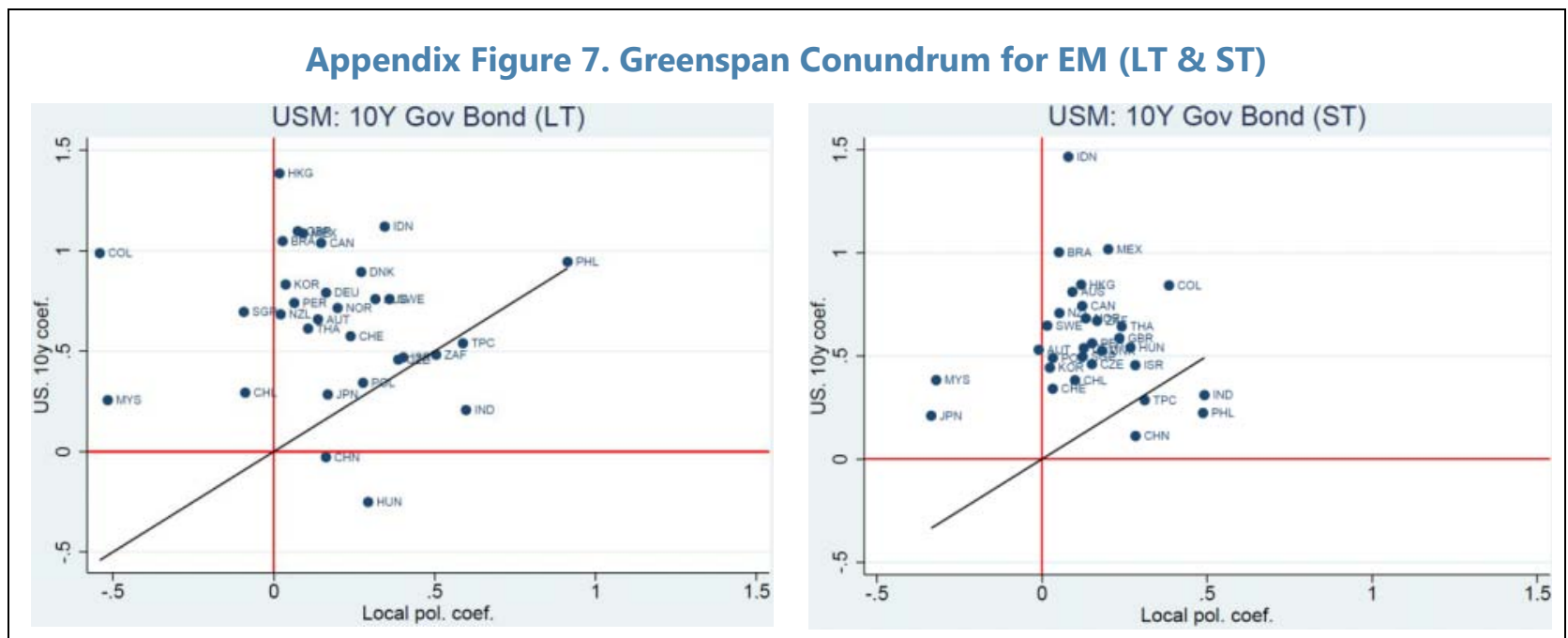

The local policy rate coefficients (horizontal) are plotted against U.S. 10-year government bond yield coefficients (vertical) in the country-specific local 10-year bond regression. Black line indicates the 45-degree line. Regression results based on levels are shown on the left, those based on one-month difference are shown on the right. 


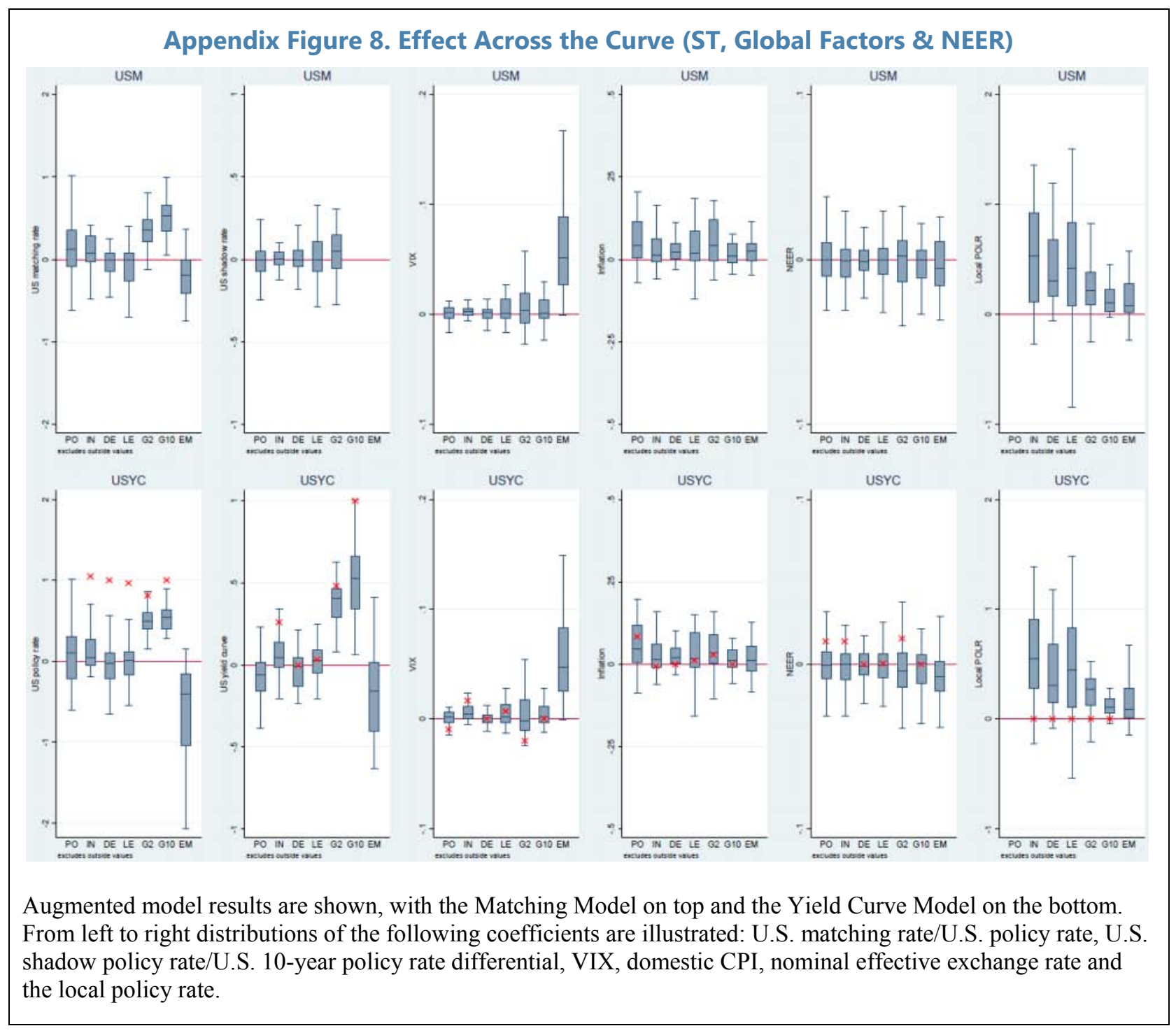


Appendix Figure 8. Effect Across the Curve (ST, Global Factors \& NEER) (Concluded)
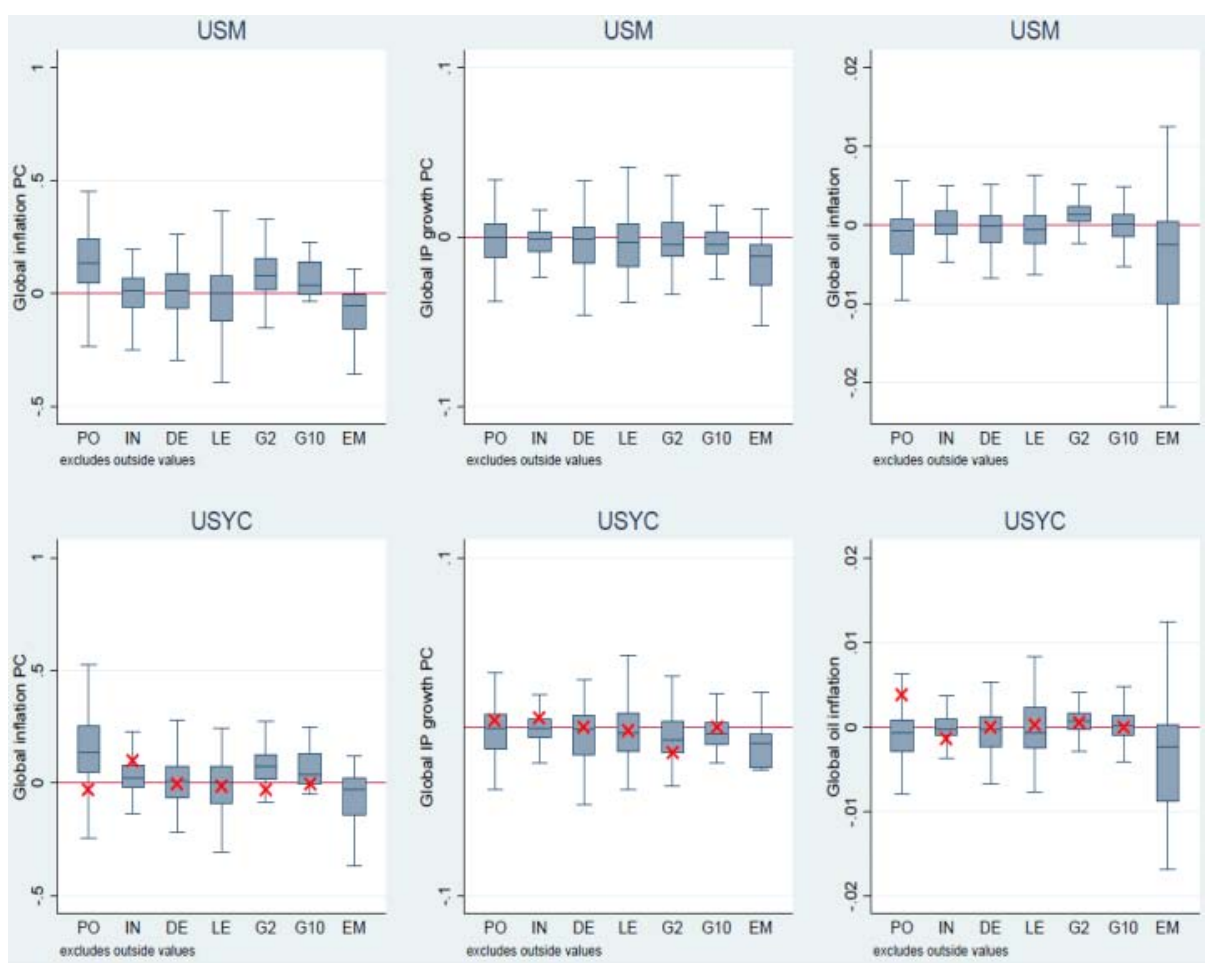

Augmented model global factor results: coefficients on global CPI ( $1^{\text {st }}$ principle component $)$, on global industrial production ( $1^{\text {st }}$ principle component) and international oil price inflation. 


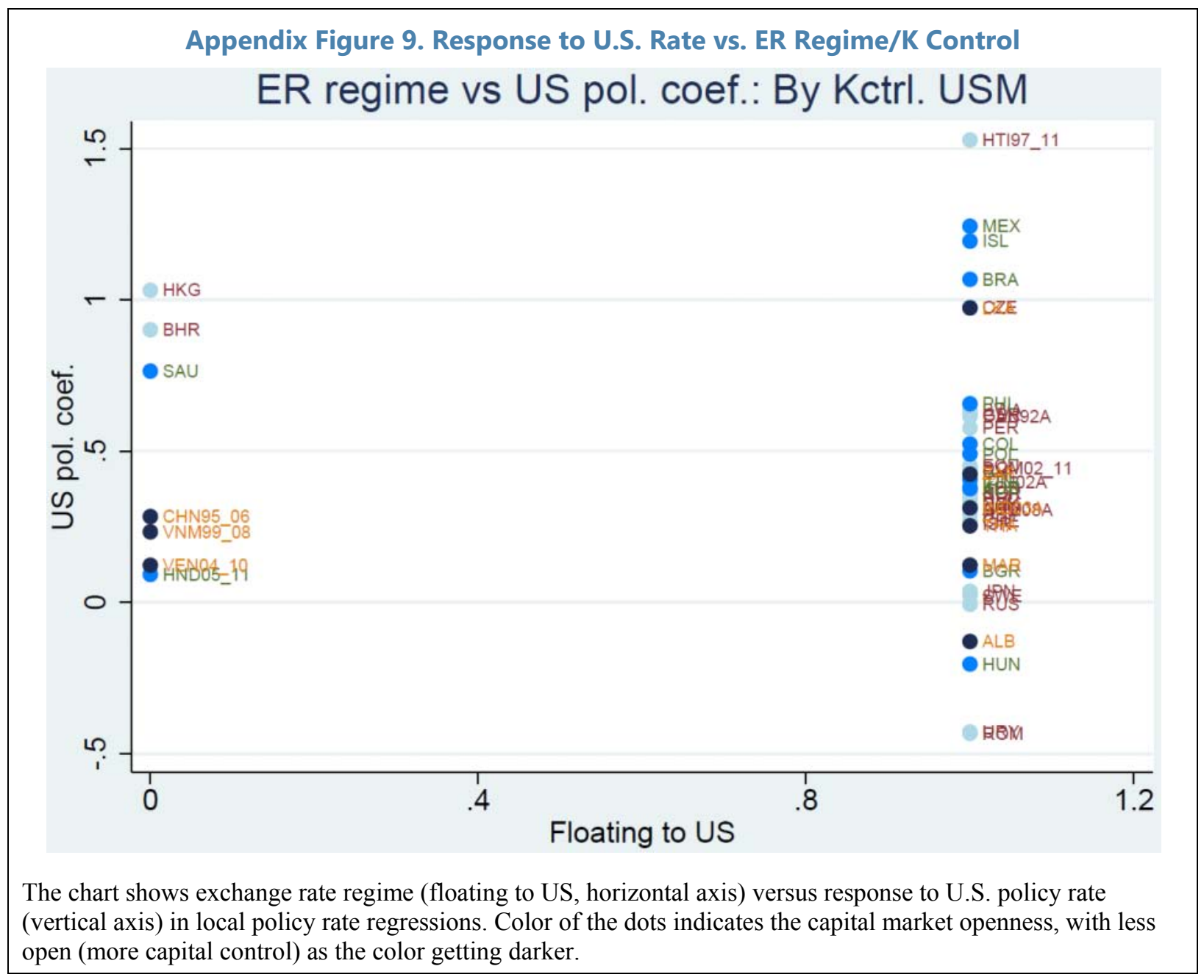

